\title{
DISTRIBUCIÓN DE ROEDORES SIGMODONTINOS (RODENTIA: CRICETIDAE) EN PASTIZALES DE NEBLINA DEL NOROESTE DE ARGENTINA
}

\author{
J. Pablo Jayat ${ }^{1}$, Pablo E. OrTiz ${ }^{2}$ y M. Daniela Miotti ${ }^{1}$ \\ ${ }^{1}$ Laboratorio de Investigaciones Ecológicas de las Yungas (LIEY), \\ Facultad de Ciencias Naturales e Instituto Miguel Lillo, UNT, CC 34, 4107 Yerba Buena, \\ Tucumán, ARGENTINA, E-mail: pjayat@proyungas.com.ar. \\ 2 Cátedra de Paleontología, Facultad de Ciencias Naturales e Instituto Miguel Lillo, UNT, \\ Miguel Lillo 205, 4000 San Miguel de Tucumán, ARGENTINA.
}

\begin{abstract}
Distribution of sigmodontine rodents (Rodentia: Cricetidae) in the cloud highland grasslands of Northwestern Argentina. The sigmodontine rodents community of cloud highland grasslands of Northwestern Argentina is reported based on records obtained by trapping, analyses of owl pellets, study of museum specimens and literature. We recorded 34 species for this environment in Argentina, which is dominated by the Tribes Akodontini and Phyllotini. The Tribes Abrothrichini, Oryzomyini and Reithrodontini are poorly represented and two incertae sedis species complete this assemblage. Only Necromys lactens and Phyllotis osilae are characteristic elements of this environment and their ecotonal areas. Akodon boliviensis, A. lutescens, A. simulator, A. spegazzinii, A. sylvanus, Necromys lasiurus, Oxymycterus paramensis, Oligoryzomys sp., Oligoryzomys cf. O. flavescens, Calomys fecundus, $C$. lepidus, C. musculinus, Andinomys edax and Neotomys ebriosus present at least one record in pure cloud highland grasslands. Necromys amoenus, Graomys edithae, G. griseoflavus, Phyllotis caprinus and Tapecomys wolffsohni are found only in the ecotone with high Andean environments. Abrothrix illuteus, Akodon aliquantulus, A. budini, A. fumeus, Necromys sp., Oxymycterus sp. and Phyllotis anitae were recorded only in the ecotone with Chaco and Yungas forest at lower altitude. Finally, Oligoryzomys chacoensis, Calomys laucha and Eligmodontia moreni were considered dubious for this environment. The sigmodontines community of cloud highland grasslands shows a latitudinal turnover, with Akodon boliviensis, A. budini, A. fumeus, A. sylvanus, Necromys amoenus, Phyllotis caprinus and Tapecomys wolffsohni restricted to northernmost region, and Abrothrix andinus, A. illuteus, Akodon aliquantulus, Calomys fecundus, Graomys edithae, G. griseoflavus, Necromys lasiurus, Necromys sp., Oxymycterus sp., Reithrodon auritus and Phyllotis anitae distributed only in the south of the study area. Recent additions to the sigmodontine fauna of this region indicate that more work is needed to reach an adequate picture of the diversity and distribution for this group in this environment.
\end{abstract}

Key words. Distribution. High altitudinal grasslands. Northwestern Argentina. Sigmodontinae.

\section{RESUMEN}

Sobre la base de registros obtenidos mediante trampeos, análisis de regurgitados de lechuzas, estudio de especímenes de colecciones y revisión bibliográfica, reportamos las especies que componen la comunidad de roedores sigmodontinos de pastizales de neblina del noroeste argentino. Se registraron 34 especies para este ambiente en Argentina, dominadas por representantes de las tribus Akodontini y 
Phyllotini. Las tribus Abrothrichini, Oryzomyini y Reithrodontini están pobremente representadas y dos especies consideradas incertae sedis completan el ensamble. Sólo Necromys lactens y Phyllotis osilae son elementos característicos de este ambiente y sus áreas ecotonales. Akodon boliviensis, A. lutescens, A. simulator, A. spegazzinii, A. sylvanus, Necromys lasiurus, Oxymycterus paramensis, Oligoryzomys sp., Oligoryzomys cf. O. flavescens, Calomys fecundus, C. lepidus, C. musculinus, Andinomys edax y Neotomys ebriosus presentaron al menos un registro en pastizales de neblina puros. Necromys amoenus, Graomys edithae, G. griseoflavus, Phyllotis caprinus y Tapecomys wolffsohni se registraron sólo en el ecotono entre estos pastizales y ambientes semiáridos de altura. Abrothrix illuteus, Akodon aliquantulus, A. budini, A. fumeus, Necromys sp., Oxymycterus sp. y Phyllotis anitae fueron registrados sólo en el ecotono con bosques chaqueños y de Yungas a menores altitudes. Finalmente, Oligoryzomys chacoensis, Calomys laucha y Eligmodontia moreni fueron considerados de presencia dudosa. Latitudinalmente, la comunidad de sigmodontinos de los pastizales muestra un reemplazo de especies, con Akodon boliviensis, A. budini, A. fumeus, A. sylvanus, Necromys amoenus, Phyllotis caprinus y Tapecomys wolffsohni restringidas al sector norte y Abrothrix andinus, A. illuteus, Akodon aliquantulus, Calomys fecundus, Graomys edithae, G. griseoflavus, Necromys lasiurus, Necromys sp., Oxymycterus sp., Reithrodon auritus y Phyllotis anitae distribuidas sólo en el sur. Recientes adiciones a la fauna de sigmodontinos del noroeste señalan la necesidad de relevamientos adicionales para alcanzar un panorama adecuado de la diversidad y distribución del grupo en este ambiente.

Palabras clave. Distribución. Pastizales de Neblina. Noroeste Argentino. Sigmodontinae.

\section{INTRODUCCIÓN}

Si bien los primeros estudios sobre sigmodontinos en el noroeste argentino datan de fines del siglo XIX y principios del XX (e.g. Thomas 1897, 1913, 1918, 1919, 1921 a, b; Cabrera 1926; Yepes 1933, 1935), el interés sostenido por este grupo en la región sólo se hizo evidente a partir de la década de 1970 (e.g. Bianchi et al. 1971; Massoia 1971, 1976; Barquez 1976; Mares 1977; Olrog 1979; Barquez et al. 1980; Mares et al. 1981; Barquez 1983; Kajon et al. 1984; Ojeda \& Mares 1989). Aunque los aportes en la última década se multiplicaron, abarcando diversas temáticas tales como ecología (e.g. Bustos 1995), taxonomía y distribución (e.g. Mares et al. 1997, Díaz 1999, Díaz et al. 1999, Díaz \& Barquez 1999, Ortiz et al. 2000, Jayat \& Pacheco 2006), anatomía (Abdala \& Díaz 2000) y paleontología (e.g. Ortiz \& Pardiñas 2001, Teta \& Ortiz 2002), el grupo continúa siendo escasamente conocido desde perspectivas elementales. Prueba de esto son las frecuentes descripciones de especies nuevas para la ciencia y las constantes adiciones a los elencos faunísticos de la región (Díaz et al. 1999; Barquez et al. 2006 a; Jayat et al. 2006, 2007a, en prep.).

Aunque en el noroeste argentino están presentes 5 de las 15 eco-regiones continentales del país (Altos Andes, Chaco Seco, Monte de Sierras y Bolsones, Puna y Selva de las Yungas; sensu Burkart et al. 1999), no existen aún publicaciones que caractericen detalladamente la fauna de sigmodontinos de las mismas. Un área fitogeográfica particularmente interesante dentro de esta complejidad ambiental son los pastizales de neblina. Debido a su posición en la cabecera de los cordones montañosos orientales de la región constituyen un ambiente fragmentado e insular, con afinidades biogeográficas discutidas (Cabrera 1976, Brown \& Grau 1993). 
Los registros que han documentado la diversidad de sigmodontinos de estos pastizales corresponden a unas pocas menciones. Estas citas provienen de revisiones taxonómicas que no han estudiado series representativas de especímenes del noroeste (Pearson 1958, Hershkovitz 1962, Olds 1988, Myers 1989, Myers et al. 1990), contribuciones sobre temáticas diferentes a la geonemia del grupo (Bianchi et al. 1971) o publicaciones generales que documentan la mastofauna de provincias o áreas protegidas (Olrog 1979, Heinonen \& Bosso 1994, Capllonch et al. 1997, Mares et al. 1997, Díaz 1999, Ortiz et al. 2000). La mayoría de estas menciones están basadas sobre escasos ejemplares provenientes de localidades concentradas en determinados sectores, por lo que no han caracterizado adecuadamente la riqueza de sigmodontinos de este ambiente en toda su extensión geográfica. Aportes recientes, sin embargo, han comenzado a clarificar la composición específica de esta comunidad, aunque enfocados en unas pocas especies en particular y no sobre toda su diversidad (Jayat et al. 2006, Jayat \& Pacheco 2006).

Sobre la base de relevamientos de campo, estudio de colecciones y revisión bibliográfica, en este trabajo se brinda una síntesis actualizada de la composición y distribución de las especies de roedores sigmodontinos que habitan los pastizales de neblina y sus áreas ecotonales en el noroeste de Argentina.

\section{MATERIAL Y MÉTODOS}

Área de estudio. El área de estudio comprende los pastizales ubicados sobre las laderas orientales y las cabeceras de los principales cordones montañosos presentes en el noroeste argentino en las provincias de Jujuy, Salta, Tucumán y Catamarca, aproximadamente entre $\operatorname{los} 22^{\circ}$ y $28^{\circ}$ de latitud $S$ y los $64^{\circ} 30^{\prime}$ y $66^{\circ} 50^{\prime}$ de longitud W. Estos cordones incluyen la Cordillera Oriental, las Sierras Subandinas, el sector norte de las Sierras Pampeanas y las Sierras Centrales. Este conjunto de sierras pueden presentar una distribución continua superando los $5000 \mathrm{~m}$ de altitud o disponerse como unidades aisladas con alturas máximas entre 2000 y $3000 \mathrm{~m}$ (Aceñolaza \& Toselli 1981). En el noroeste argentino, los pastizales de neblina cuentan con una superficie aproximada de $14000 \mathrm{~km}^{2}$ y se desarrollan entre $1500 \mathrm{y}$ $3000 \mathrm{~m}$ de altitud.

El clima de esta región se caracteriza por un régimen biestacional con las lluvias concentradas en los meses de verano y principios de otoño. Aunque en zonas de ecotono con bosques montanos los valores medios anuales de precipitacion pueden superar los $1500 \mathrm{~mm}$, durante el cuatrimestre más seco (Junio-Septiembre) pueden registrarse valores apenas por encima de los $60 \mathrm{~mm}$. Una fuente importante de humedad para el suelo, sobre todo en los meses de sequía, son la intercepción de niebla y el rocío (Grau \& Veblen 2000). Las temperaturas son también muy variables entre los períodos estival e invernal, existiendo nevadas ocasionales durante el invierno. A un nivel regional, las temperaturas máximas medias anuales pueden 
alcanzar los $20^{\circ} \mathrm{C}$ en algunas zonas, mientras que las mínimas medias anuales pueden estar por debajo de $\operatorname{los} 8^{\circ} \mathrm{C}$.

La vegetación se caracteriza por una flora muy diversa que constituye una comunidad herbácea biestratificada formada por pastos duros de crecimiento fasciculado. Entre las gramíneas más abundantes destacan Festuca hieronymi, Deyeuxia rosea, Deyeuxia polygama, Chloris distichophylla, Lamphrothyrsus hieronymi, Paspalum lineispatha, Anthaenanthiopsis fiebrigii y Stipa tucumana (Cabrera 1976, Vervoorst 1982).

En su límite altitudinal inferior los pastizales entran en contacto con los bosques montanos de Yungas mientras que en el superior se funden con los pastizales altoandinos y de la estepa puneña (Cabrera \& Willink 1980, Brown \& Grau 1993). La zona de contacto entre los pastizales de neblina y los bosques montanos se caracteriza por un aporte importante de humedad que favorece una abundante cobertura y gran complejidad estructural. En este sector intergradan pastizales con bosques casi monoespecíficos de aliso (Alnus acuminata), pino del cerro (Podocarpus parlatorei) o queñoa (Polylepis spp.). En su límite altitudinal superior los pastizales de neblina se funden con comunidades empobrecidas de gramíneas de la estepa puneña y los pastizales altoandinos. En unos pocos sitios también pueden limitar con sectores de Prepuna. En estas zonas, las condiciones de menor temperatura, menor humedad y el sustrato rocoso impiden el desarrollo de las densas comunidades de gramíneas que proliferan a menor altitud, predominando el suelo desnudo, las plantas en cojín y, en algunos casos, cactus de escaso desarrollo.

Obtención de registros. Durante el período comprendido entre 1999 y 2006 se realizaron 41 campañas de muestreo a 48 localidades en pastizales de neblina y áreas ecotonales que abarcan todo su gradiente latitudinal y altitudinal en el noroeste argentino (Fig. 1, Apéndices 1 y 2). Las capturas se realizaron mediante trampas de captura viva tipo Sherman y de captura muerta Museum Special dispuestas en transectas. Los ejemplares capturados fueron taxidermizados siguiendo protocolos estándar (Mares et al. 1989) y llevados al laboratorio para su identificación. Esta tarea se llevó a cabo con la ayuda de descripciones originales de las especies, bibliografía (e.g. Yepes 1935, Pearson 1958, Hershkovitz 1962, Olds 1988, Myers 1989, Myers et al. 1990) y comparación con ejemplares de colecciones mastozoológicas. Además, numerosos especímenes fueron obtenidos a través del análisis de egagrópilas de lechuzas. Registros adicionales se obtuvieron a partir del estudio de colecciones y revisión bibliográfica. Las colecciones argentinas estudiadas fueron la Colección de Mamíferos Lillo (CML), San Miguel de Tucumán; el Museo Municipal de Ciencias Naturales "Lorenzo Scaglia" (MMPMa), Mar del Plata, y el Museo de Ciencias Naturales "Bernardino Rivadavia" (MACN), Buenos Aires. 


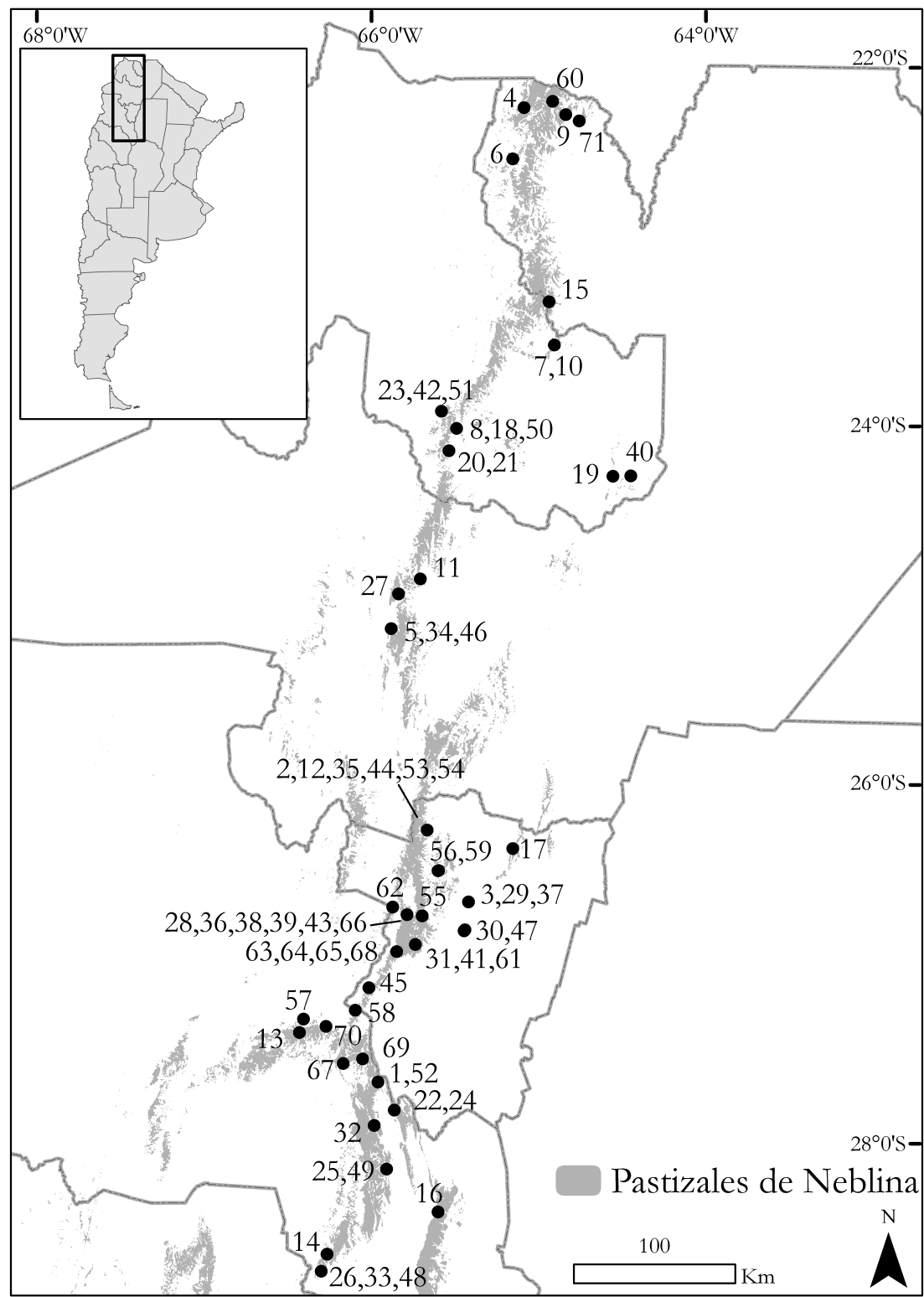

Figura 1. Mapa con las localidades de registro de los especímenes de roedores sigmodontinos de pastizales de neblina del noroeste argentino. En gris se indican los pastizales de neblina. 
Tabla 1. Distribución de roedores sigmodontinos en los ambientes de captura del área de estudio.

T-A: transición ambientes abiertos-pastizales de neblina; PN: pastizales de neblina puros;

T-B: transición pastizales de neblina-ambientes boscosos. El ambiente mencionado para las especies aquí consideradas de presencia dudosa se indica con una letra D.

\begin{tabular}{|c|c|c|c|}
\hline \multirow[b]{2}{*}{ Especies } & \multicolumn{3}{|c|}{ Ambientes } \\
\hline & T-A & PN & T-B \\
\hline Abrothrix andinus & $\mathrm{X}$ & & \\
\hline Abrothrix illuteus & & & $\mathrm{X}$ \\
\hline Akodon aliquantulus & & & $\mathrm{X}$ \\
\hline Akodon boliviensis & & $\mathrm{X}$ & $\mathrm{X}$ \\
\hline Akodon budini & & & $\mathrm{X}$ \\
\hline Akodon fumeus & & & $\mathrm{X}$ \\
\hline Akodon lutescens & $\mathrm{X}$ & $\mathrm{X}$ & $\mathrm{X}$ \\
\hline Akodon simulator & $\mathrm{X}$ & $\mathrm{X}$ & $\mathrm{X}$ \\
\hline Akodon spegazzinii & $\mathrm{X}$ & $\mathrm{X}$ & $\mathrm{X}$ \\
\hline Akodon sylvanus & & $\mathrm{X}$ & $\mathrm{X}$ \\
\hline Necromys amoenus & $\mathrm{X}$ & & \\
\hline Necromys lactens & $\mathrm{X}$ & $\mathrm{X}$ & $\mathrm{X}$ \\
\hline Necromys sp. & & & $\mathrm{X}$ \\
\hline Necromys lasiurus & & $\mathrm{X}$ & \\
\hline Oxymycterus paramensis & $\mathrm{X}$ & $\mathrm{X}$ & $\mathrm{X}$ \\
\hline Oxymycterus sp. & & & $\mathrm{X}$ \\
\hline Oligoryzomys cf. O. flavescens & & $\mathrm{X}$ & $\mathrm{X}$ \\
\hline Oligoryzomys chacoensis & $\mathrm{D}$ & & \\
\hline Oligoryzomys sp. & & $\mathrm{X}$ & $\mathrm{X}$ \\
\hline Calomys laucha & & & $\mathrm{D}$ \\
\hline Calomys lepidus & $\mathrm{X}$ & $\mathrm{X}$ & \\
\hline Calomys musculinus & $\mathrm{X}$ & $\mathrm{X}$ & $\mathrm{X}$ \\
\hline Calomys fecundus & $\mathrm{X}$ & & $\mathrm{X}$ \\
\hline Eligmodontia moreni & $\mathrm{D}$ & & \\
\hline Graomys edithae & $\mathrm{X}$ & & \\
\hline Graomys griseoflavus & $\mathrm{X}$ & & \\
\hline Phyllotis anitae & & & $\mathrm{X}$ \\
\hline Phyllotis caprinus & $\mathrm{X}$ & & \\
\hline Phyllotis osilae & $\mathrm{X}$ & $\mathrm{X}$ & $\mathrm{X}$ \\
\hline Phyllotis xanthopygus & $\mathrm{X}$ & & $\mathrm{X}$ \\
\hline Reithrodon auritus & $\mathrm{X}$ & & \\
\hline Tapecomys wolffsohni & $\mathrm{X}$ & & \\
\hline Andinomys edax & $\mathrm{X}$ & $\mathrm{X}$ & $\mathrm{X}$ \\
\hline Neotomys ebriosus & & $\mathrm{X}$ & \\
\hline Total de especies & 18 & 15 & 21 \\
\hline
\end{tabular}


Parte del material colectado presenta aún numeración de campo (JPJ = catálogo de J. Pablo Jayat; PEO = catálogo de Pablo E. Ortiz; PEO-E = catálogo de egagrópilas de Pablo E. Ortiz) y será depositado en la CML y el MACN.

Tratamiento de las especies. El criterio taxonómico adoptado sigue los lineamientos básicos de Barquez et al. (2006b), con algunas excepciones que se mencionan en el tratamiento de cada una de las especies.

Las especies están divididas en 3 grupos: a) aquellas que tienen al menos un registro para pastizales de neblina; $b$ ) especies que sólo se encuentran en áreas ecotonales con otros ambientes; c) aquellas consideradas de presencia dudosa (Tabla 1). Para cada especie se brinda un resumen de su distribución en Argentina, la distribución registrada en los pastizales de neblina y ambientes ecotonales y comentarios taxonómicos o relacionados con la importancia de los nuevos registros. En el apéndice 3, siguiendo el mismo ordenamiento en grupos, se brindan los especímenes examinados y registros adicionales para cada especie.

Las localidades de colecta de los ejemplares examinados y los registros adicionales de la bibliografía se resumen en el apéndice 1 y se indican gráficamente en un mapa (Fig. 1). Las localidades imprecisas y aquellas que no pudieron ser ubicadas no llevan número y se listan por separado (Apéndice 2).

\title{
RESULTADOS \\ Especies de presencia confirmada en pastizales de neblina
}

\author{
Orden Rodentia Bowdich 1821 \\ Familia Cricetidae Rochebrune 1883 \\ Subfamilia Sigmodontinae Wagner 1843 \\ Tribu Akodontini Vorontsov 1959 \\ Akodon boliviensis Meyen 1833
}

Distribución en Argentina. Registrada en la provincia de Salta (Jayat et al. 2006).

Distribución en pastizales de neblina. Extremo norte de la región, con su límite sur de distribución conocido a $23^{\circ} 19^{\prime} \mathrm{S}$. Se encuentra en ambientes de pastizales puros y en ecotono con ambientes altoandinos, por encima de $2400 \mathrm{~m}$. En Pampa Verde las condiciones de humedad propician la existencia de pastizales con buena cobertura. Rodeo Pampa corresponde a una transición entre pastizales de neblina y pastizales altoandinos, caracterizados por escasa cobertura vegetal y abundantes rocas (Fig. 2 b).

Comentarios. Estudios moleculares indican que el registro de esta especie para los alrededores de Escoipe (Jayat et al. 2006) es incorrecto, debiendo referirse los ejemplares a A. spegazzinii (véase el tratamiento de esta última especie).

\section{Akodon lutescens J. A. Allen 1901}

Distribución en Argentina. Amplia distribución en Catamarca, Jujuy, Salta y Tucumán, entre 400 y $3100 \mathrm{~m}$, para ambientes de Chaco Seco y todos los pisos altitudinales de Yungas 
(Capllonch et al. 1997, Mares et al. 1997, Díaz 1999, Díaz et al. 2000, Pardiñas et al. 2006, Díaz \& Barquez 2007).

Distribución en pastizales de neblina. Desde el extremo norte, en el límite con Bolivia, hasta el sur de Catamarca. Ocupa todo el gradiente altitudinal, desde $1500 \mathrm{~m}$, en el límite con los bosques montanos, hasta $3100 \mathrm{~m}$, en transición con ambientes de Prepuna y pastizales altoandinos (Fig. 2 a, b, c). Sin embargo, la mayoría de los registros están por debajo de 2500 $\mathrm{m}$, donde la especie es notoriamente más abundante.

Comentarios. El ejemplar CML 1734, aquí listado como Akodon lutescens, fue considerado como A. fumeus por Díaz (1999). Este espécimen muestra un cráneo muy pequeño, con serie molar corta $(3.8 \mathrm{~mm})$ y fosa mesopterigoides, región interorbital, caja craneana y placa cigomática muy estrechas (Tabla 2). Todas estas características claramente lo diferencian de $A$. fumeus.

\section{Akodon simulator Thomas 1916}

Distribución en Argentina. Amplia distribución en el noroeste argentino, en Catamarca, Jujuy, La Rioja, Salta, Santiago del Estero y Tucumán, entre 400 y 3000 m (Myers 1989, Capllonch et al. 1997, Mares et al. 1997, Díaz 1999, Díaz et al. 2000, Pardiñas et al. 2006, Díaz \& Barquez 2007), habitando en Chaco, Monte y todos los pisos altitudinales de Yungas.

Distribución en pastizales de neblina. Desde los $24^{\circ} 18^{\prime} \mathrm{S}$, en el sur de Jujuy, hasta el sur de Catamarca, en el límite con La Rioja. Más abundante en el límite altitudinal inferior, por debajo de $2000 \mathrm{~m}$. Si bien suele capturarse en pastizales puros (Fig. 2 a), frecuenta mayormente ambientes de ecotono entre los pastizales y el bosque montano.

Comentarios. Aunque Myers (1989) reconoció tres subespecies de A. simulator (A.s. simulator, A. s. tartareus y A. s. glaucinus) algunos autores han considerado recientemente a tartareus como especie plena sobre bases morfológicas y de simpatría (Díaz 1999, Díaz \& Barquez 2007). Recientes análisis moleculares del gen que codifica para el citocromo b (Jayat et al. datos no publicados), que incluyeron ejemplares morfológicamente referibles a $A$. $s$. tartareus y A. s. glaucinus de pastizales de neblina de Jujuy y Catamarca y especímenes topotipos de las tres formas nominales, contradicen esta última postura. Estos estudios demuestran una considerable variación en caracteres externos y craneales en A. simulator a lo largo de su geonemia.

\section{Akodon spegazzinii Thomas 1897}

Distribución en Argentina. Registrada para Catamarca, La Rioja, Salta, y Tucumán para casi todo el gradiente altitudinal, desde $400 \mathrm{~m}$ en la zona de transición entre el Chaco y las Yungas hasta más de $3000 \mathrm{~m}$ (Myers et al. 1990, Capllonch et al. 1997, Mares et al. 1997, Díaz et al. 2000, Pardiñas et al. 2006).

Distribución en pastizales de neblina. Numerosas localidades mayormente agrupadas en el sector sur del área de estudio, desde el extremo sur de Catamarca hasta el centro de la provincia de Salta y con su límite norte de distribución en pastizales a los $24^{\circ} 53^{\prime} \mathrm{S}$. Ocupa todo el gradiente altitudinal, entre 1500 y más de $3300 \mathrm{~m}$. Además, habita los ecotonos con el bosque montano, el pastizal altoandino y la Prepuna.

Comentarios. Es, junto a Phyllotis osilae, la especie dominante en los pastizales del centro y sur de la región. Akodon alterus, con localidad tipo en Otro Cerro (Catamarca), un ambiente ecotonal de pastizales de neblina, presenta un estatus taxonómico confuso y es actualmente 
considerada conespecífica con A. spegazzinii (Musser \& Carleton 2005, Pardiñas et al. 2006), postura coincidente con estudios morfológicos y moleculares en curso que incluyen especímenes de proximidades de su localidad tipo.

\section{Akodon sylvanus Thomas 1921}

Distribución en Argentina. Restringida a Salta y Jujuy, con la mayor parte de sus registros en áreas boscosas de Yungas, entre 700 y 2300 m (Thomas 1921a; Díaz 1999; Pardiñas et al. 2006; Díaz \& Barquez 2007; Jayat et al. 2006, en prensa).

Distribución en pastizales de neblina. Parece ser un habitante de zonas bajas, por debajo de los $2400 \mathrm{~m}$ en áreas de ecotono entre pastizales y bosques. Fue registrada en parches pequeños de pastizales ubicados en áreas cumbrales de las Sierras Subandinas en la provincia de Jujuy.

Comentarios. Conocida previamente sólo para bosques de Yungas, ha sido recientemente registrada en pastizales por encima de $2000 \mathrm{~m}$ (Jayat et al. 2006).

\section{Necromys lactens (Thomas 1918)}

Distribución en Argentina. En Jujuy, Salta, Tucumán y Catamarca (Mares et al. 1997, Díaz 1999, Díaz et al. 2000, Jayat et al. 2006, Díaz \& Barquez 2007), restringida a ambientes de pastizales de neblina y sus ecotonos (Jayat \& Pacheco 2006).

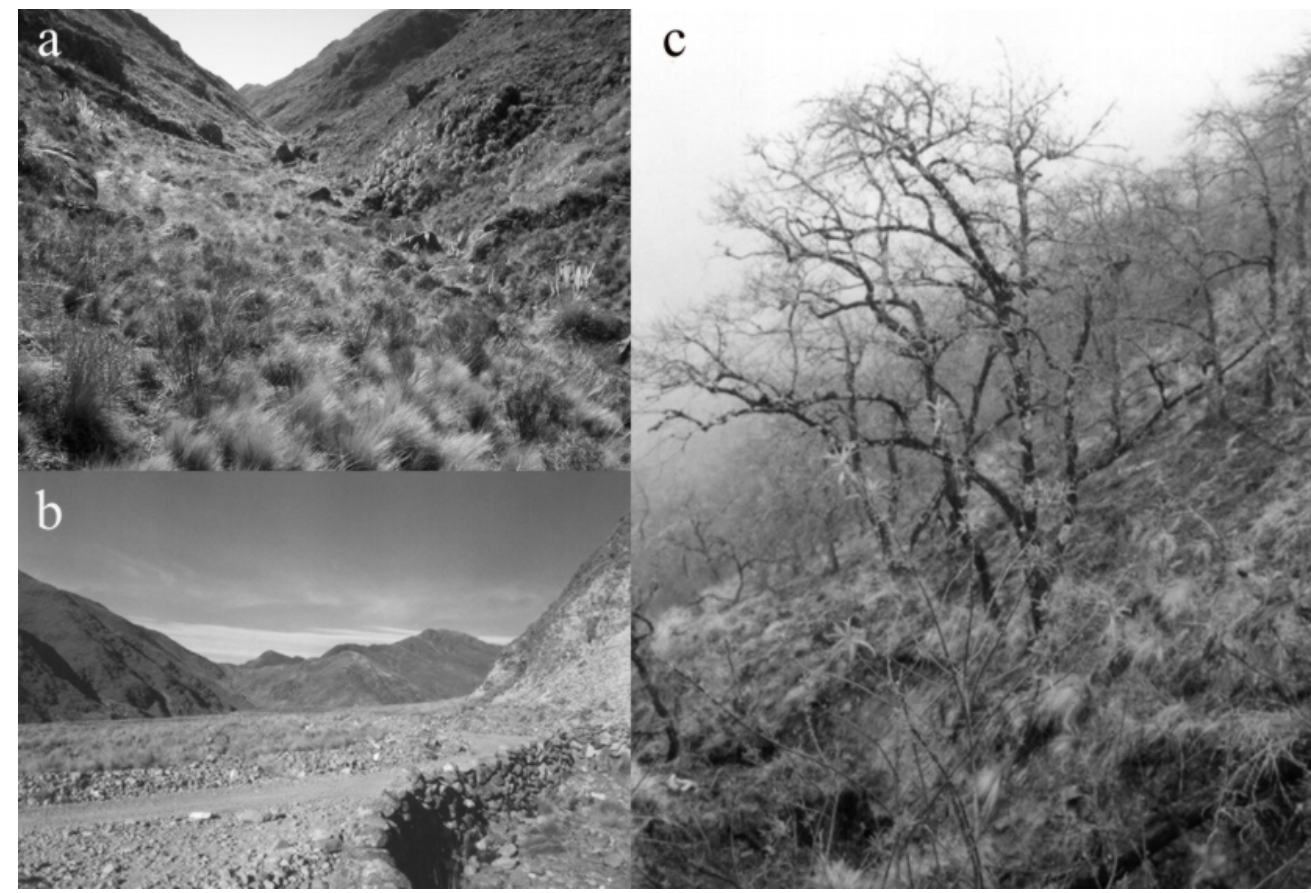

Figura 2. Aspectos del ambiente de pastizales de neblina y areas ecotonales: a) pastizales de neblina puros (extremo sur de la Sierra de Ambato, Catamarca); b) ecotono pastizal de neblina-pastizal altoandino (Rodeo Pampa, 3100 m, Salta); c) ecotono pastizal de neblina- bosque montano de Yungas (Hualinchay, Tucumán). 
Distribución en pastizales de neblina. Registrado en numerosas localidades en el área de estudio a lo largo de todo el gradiente altitudinal y latitudinal. Suele también capturarse en áreas ecotonales en zonas bajas linderas con bosques de Yungas y en áreas a más de $3000 \mathrm{~m}$ que limitan con ambientes abiertos de altura.

Comentarios. Algunas menciones en ambientes diferentes a los pastizales fueron consideradas dudosas y discutidas en Jayat \& Pacheco (2006).

\section{Necromys lasiurus (Lund 1841)}

Distribución en Argentina. En las provincias de Catamarca, Chaco, Formosa, Misiones, Salta y Tucumán (Jayat et al. 2006, Pardiñas et al. 2006).

Distribución en pastizales de neblina. Registrada en Catamarca sobre la ladera occidental de la Sierra de Narváez a 1900 m, en pastizales con buena cobertura entremezclados con bosques de aliso (Jayat et al. 2006).

Comentarios. Aunque $N$. lasiurus ha sido mencionado como probable para algunas provincias del noroeste argentino (Mares et al. 1981, Ojeda \& Mares 1989, Díaz et al. 2000), la mayor parte de sus registros en esta región deben ser debidamente documentados.

\section{Oxymycterus paramensis Thomas 1902}

Distribución en Argentina. En Jujuy, Salta y Tucumán, principalmente en áreas de Yungas (Barquez 1976, Díaz 1999, Díaz et al. 2000, Pardiñas et al. 2006, Díaz \& Barquez 2007).

Distribución en pastizales de neblina. La mayoría de sus registros provienen del sector norte, en Salta y Jujuy, desde 1400 hasta más de $3000 \mathrm{~m}$. Aunque presente en todo el rango altitudinal, $O$. paramensis es poco frecuente en pastizales de neblina puros y, con la excepción de Chilcayoc (Jujuy), ha sido generalmente capturada en proximidades de ambientes boscosos.

Comentarios. El registro del Taficillo, en la provincia de Tucumán, representa la segunda cita de la especie para esta provincia.

\section{Tribu Oryzomyini Vorontsov 1959 \\ Oligoryzomys cf. O. flavescens}

Distribución en Argentina. Para Oligoryzomys flavescens se ha mencionado una amplia distribución en el país (Cirignoli et al. 2006). Rivera et al. (2007) han recuperado dentro de Oligoryzomys tres clados pertenecientes al "complejo flavescens" con amplia geonemia en el país. Uno de estos clados ha sido documentado en el noroeste argentino en las provincias de Jujuy y Salta, para ambientes de Yungas.

Distribución en pastizales de neblina. Desde 1400 hasta 2400 m, principalmente asociada a zonas de ecotono con ambientes boscosos o arbustivos del piso superior de Yungas. Ha sido colectada en pastizales desde el límite con Bolivia hasta el sur de Catamarca pero carece de registros para la zona central de Salta.

Comentarios. Los ejemplares registrados presentan valores morfométricos y morfología similares a los de $O$. flavescens, especie a la cual fueron referidos previamente los especímenes pequeños de Oligoryzomys del noroeste argentino (e.g. Capllonch et al. 1997, Mares et al. 1997, Díaz 1999, Díaz et al. 2000, Gil \& Heinonen 2003, Díaz \& Barquez 2007). Sin embargo, Gonzalez Ittig et al. (2002) han señalado la presencia de formas diferentes a $O$. flavescens en Salta y Jujuy. Dado que la resolución taxonómica de esta entidad necesita estudios adicionales (véase Rivera et al. 2007), una identificación específica inequívoca de estos ejemplares parece apresurada. 


\section{Oligoryzomys sp.}

Distribución en Argentina. Nuestras observaciones indican que esta entidad está ampliamente distribuida en Catamarca, Jujuy, Salta y Tucumán, principalmente en Yungas y pastizales de neblina.

Distribución en pastizales de neblina. Registrada en un amplio gradiente altitudinal desde 1400 a $2700 \mathrm{~m}$. No obstante, la mayoría de los registros se encuentran por debajo de $2000 \mathrm{~m}$, asociados a zonas de ecotono con el bosque montano. Se extiende además sobre la mayor parte del gradiente latitudinal, con la excepción del extremo norte de la región.

Comentarios. Las formas de Oligoryzomys de tamaño grande en el noroeste argentino han sido tratadas en la literatura como O. destructor (e.g. Capllonch et al. 1997, Díaz 1999, Díaz et al. 2000) y como O. longicaudatus (e.g. Cabrera 1961, Ojeda \& Mares 1989, Mares et al. 1997, Díaz 1999). Esta última ha sido restringida a Chile y sur de Argentina (Espinosa \& Reig 1991, González Ittig et al. 2002, Rivera et al. 2007) en tanto que la asignación a O. destructor no ha sido adecuadamente fundamentada (Cirignoli et al. 2006). Análisis moleculares preliminares indican que los especímenes aquí tratados no corresponden a esta última especie (M. I. Carma com. pers.). Tampoco debe descartarse su probable pertenencia a O. brendae, una forma pobremente descripta para Tucumán (Massoia 1998).

\section{Tribu Phyllotini Vorontsov 1959 \\ Calomys lepidus (Thomas 1884)}

Distribución en Argentina. En Jujuy, Salta y Tucumán, en áreas de pastizales y arbustales por encima de 3000 m, principalmente en sectores de Puna y Altoandinos (Hershkovitz 1962, Barquez et al. 1991, Díaz 1999, Cirignoli et al. 2001, Díaz et al. 2006, Díaz \& Barquez 2007).

Distribución en pastizales de neblina. El único ejemplar capturado proviene de pastizales del centro de Salta, a menos de $2700 \mathrm{~m}$. Especimenes adicionales en el área de Valle Encantado fueron recuperados de egagrópilas de lechuzas (Ortiz et al. 2000).

Comentarios. Aquí se presenta el primer registro de C. lepidus por debajo de $3000 \mathrm{~m}$ y la segunda cita para pastizales de neblina.

\section{Calomys musculinus (Thomas 1913)}

Distribución en Argentina. Amplia distribución desde el norte de Santa Cruz hasta el extremo norte, a excepción de las provincias mesopotámicas. Habita una gran variedad de ambientes, desde la estepa patagónica y pastizal pampeano hasta bosques chaqueños, de yungas y ambientes de altura en la Prepuna y Puna (Mares et al. 1997, Díaz 1999, Díaz et al. 2000, Díaz et al. 2006, Jayat et al. 2006, Díaz \& Barquez 2007).

Distribución en pastizales de neblina. Casi todo el gradiente latitudinal, desde el sur de Jujuy, a 23 23' S, hasta el extremo sur de Catamarca entre 1700 y $3000 \mathrm{~m}$, con la mayor parte de sus registros por encima de $2000 \mathrm{~m}$. Es abundante en áreas de pastizales degradados y en el límite altitudinal superior, en el ecotono con ambientes semiáridos de escasa cobertura vegetal y predominio de sustratos rocosos.

Comentarios. Sobre la base de restos recuperados de egagrópilas de lechuzas Ortiz et al. (2000) citaron a Calomys cf. C. musculinus para Valle Encantado y Ortiz \& Pardiñas (2001) a Calomys laucha-musculinus para La Angostura. Este material probablemente corresponda a C. musculinus. Del mismo modo, es probable que la cita de Calomys laucha para Ñorco, 1500-2000 m (Hershkovitz 1962) sea referible a esta especie. La presencia de C. laucha en el 
noroeste de Argentina debe aún ser debidamente documentada, existiendo sólo registros no confirmados para el Chaco Seco (Díaz et al. 2006).

\section{Phyllotis osilae J. A. Allen 1901}

Distribución en Argentina. En Catamarca, Jujuy, Salta y Tucumán, entre 1400 y 3100 m, principalmente en ambientes de pastizales de neblina y áreas ecotonales (Pearson 1958, Jayat \& Pacheco 2006, Jayat et al. 2006).

Distribución en pastizales de neblina. Típica de este ambiente, desde 1400 hasta algo más de $3000 \mathrm{~m}$ y desde el límite con Bolivia hasta el sur de Catamarca, cerca del límite con La Rioja (Jayat \& Pacheco, 2006), ocupando, además, la transición con el bosque montano de Yungas y ambientes de altura como Prepuna, Puna y Monte, donde los pastizales están empobrecidos y la especie es notablemente menos abundante.

Comentarios. Díaz (1999) y Díaz \& Barquez (2007) citaron a P. osilae para áreas atípicas para la especie en la Prepuna y Puna en Jujuy. Una discusión detallada sobre estos registros puede consultarse en Jayat \& Pacheco (2006).

\section{Sigmodontinae incertae sedis (sensu D'Elía et al. 2006) Andinomys edax Thomas 1902}

Distribución en Argentina. Catamarca, Jujuy, Salta y Tucumán en una amplia variedad de ambientes incluyendo Yungas, pastizales de altura, Prepuna y Puna (Yepes 1935, Hershkovitz 1962, Barquez et al. 1991, Mares et al. 1997, Díaz 1999, Díaz et al. 2000, Ortiz et al. 2000, Díaz \& Barquez 2007).

Distribución en pastizales de neblina. Todo el gradiente altitudinal, entre 1700 y $3000 \mathrm{~m}$, desde la zona de Los Toldos, en el extremo norte de Salta, hasta el extremo sur de Catamarca, en Otro Cerro.

Comentarios. Dos subespecies fueron reconocidas por Yepes (1935) para Argentina, $A$. edax edax y A. edax lineicaudatus. Díaz (1999) sobre la base de su simpatría en áreas de Prepuna en Jujuy elevó lineicaudatus a rango de especie (véase también Díaz \& Barquez 2007). Los ejemplares capturados en pastizales de neblina y áreas ecotonales con bosques de Yungas muestran caracteres combinados y superposición de los valores morfométricos mencionados para ambas subespecies lo cual sugiere la presencia de flujo génico entre las poblaciones de ambientes abiertos de altura y aquellas de áreas boscosas de Yungas. Además, las sutiles diferencias entre ambas formas y la ausencia de estudios taxonómicos sugieren mantener, al menos por el momento, la postura original de Yepes (1935).

\section{Neotomys ebriosus Thomas 1894}

Distribución en Argentina. Citada principalmente para "vegas" en ambientes puneños y altoandinos por encima de 3000 m en Catamarca, Jujuy, Salta y San Juan (Thomas 1921b, 1926; Sanborn 1947; Barquez 1983; Díaz 1999; Díaz et al. 2000; Pardiñas \& Ortiz 2001; Díaz \& Barquez 2007).

Distribución en pastizales de neblina. Los únicos ejemplares capturados provienen de la Cuesta del Obispo, Salta, en pastizales de neblina típicos a $2700 \mathrm{~m}$, una altitud inusual y un ambiente diferente al reconocido previamente para la especie. El sitio presenta una buena cobertura vegetal, con grandes matas de pasto sobre una ladera húmeda expuesta al sudeste.

Comentarios. El material de Valle Encantado fue recuperado de egagrópilas de lechuzas en pastizales degradados por pastoreo (Ortiz et al. 2000). 


\title{
Especies de presencia marginal en pastizales de neblina
}

\author{
Orden Rodentia Bowdich 1821 \\ Familia Cricetidae Rochebrune 1883 \\ Subfamilia Sigmodontinae Wagner 1843 \\ Abrotrichini D'Elía et al. 2007 \\ Abrothrix andinus (Philippi 1858)
}

Distribución en Argentina. Principalmente áreas altoandinas por encima de $3500 \mathrm{~m}$, con registros para Puna, Prepuna y Altos Andes en Catamarca, Jujuy, Mendoza, Salta y Tucumán (Thomas 1926, Díaz 1999, Teta et al. 2006, Díaz \& Barquez 2007).

Distribución asociada a pastizales de neblina. Hasta el momento sólo registrado en el extremo sur del área de estudio. Minas Capillitas y El Infiernillo representan ecotonos de pastizales con ambientes abiertos de altura.

Comentarios. El registro de El Infiernillo es el único para pastizales ecotonales relativamente húmedos pero, a pesar de intensos muestreos, no volvió a ser registrada en el área.

\section{Abrothrix illuteus Thomas 1925}

Distribución en Argentina. Extremo austral de las Yungas, principalmente por encima de 1000 m, en Catamarca y Tucumán (Capllonch et al. 1997, Mares et al. 1997, Jayat et al. 2006, Teta et al. 2006).

Distribución asociada a pastizales de neblina. Zona de transición entre pastizales y bosques montanos entre 1800 y $2300 \mathrm{~m}$ (Fig. 2 c).

Comentarios. A. illuteus es endémica del extremo sur de las Yungas, con todos sus registros en una delgada franja latitudinal de menos de $150 \mathrm{~km}$ de extensión.

\section{Tribu Akodontini Vorontsov 1959}

\section{Akodon aliquantulus Díaz, Barquez, Braun \& Mares 1999}

Distribución en Argentina. Localidad tipo y escasos registros adicionales en Tucumán (Díaz et al. 1999, Pardiñas et al. 2006).

Distribución asociada a pastizales de neblina. Región ecotonal entre pastizales y bosque montano de Yungas a $1700 \mathrm{~m}$, en comunidades de gramíneas dominadas por Festuca hyeronimii y bosques de Podocarpus parlatorei y Alnus acuminata.

Comentarios. Especie descripta sobre la base de sólo dos ejemplares y únicamente a partir de rasgos morfométricos y morfología externa. Ha sido diferenciada de A. lutescens, una especie morfológicamente similar, por caracteres sutiles y altamente variables en la mayoría de las especies de Akodon de la región. Aunque los dos individuos fueron considerados por Díaz et al. (1999) como adultos viejos (edad 5), el examen de los ejemplares sugiere que deben ser asignados a la clase de edad 4 de Myers (1989). De este modo, las diferencias morfométricas respecto de $A$. lutescens se diluyen, aspecto observado en la tabla 1 de la publicación original donde la mayoría de los valores para $A$. aliquantulus se encuentran dentro del rango observado para ejemplares de $A$. lutescens de esta edad. Más aún, algunas de las medidas craneanas menos variables con el incremento de edad utilizadas en la diagnosis (e.g. ancho de la caja craneana y longitud de la serie molar) muestran solapamiento con el rango observado para ejemplares de A. lutescens de edad 5. Aunque aceptada como 
válida en listas recientes (Musser \& Carleton 2005, Pardiñas et al. 2006), el estatus de $A$. aliquantulus, así como el de otras formas nominales del género en la región (e.g. alterus, caenosus, leucolimnaeus), debe ser debidamente evaluado en un contexto de una revisión integral (Musser \& Carleton 2005). La ausencia de estudios cariotípicos, moleculares y de anatomía blanda de ejemplares topotípicos de esta forma complican aún más una evaluación sólida de su estatus taxonómico.

\section{Akodon budini (Thomas 1918)}

Distribución en Argentina. Escasas localidades en ambientes de Yungas en Jujuy y Salta (Thomas 1918, Heinonen \& Bosso 1994, Díaz 1999, Jayat et al. 2006, Díaz \& Barquez 2007).

Distribución asociada a pastizales de neblina. Vinculada más a áreas boscosas que a ambientes de pastizales. Ha sido capturada en áreas ecotonales entre bosque montano y pastizales entre 1500 y $2600 \mathrm{~m}$. Los ejemplares de Pampa Verde fueron capturados en quebradas húmedas densamente cubiertas de pastos y arbustos lindantes con pastizales puros. Akodon budini sólo ha sido registrado en el norte del área de estudio, con su límite sur de distribución en los pastizales a $24^{\circ} 2$ ' $\mathrm{S}$.

Comentarios. Díaz (1999) y Díaz \& Barquez (2007) consideraron ejemplares de El Duraznillo como A. fumeus. El examen de 14 de los 15 especímenes referidos permitió reidentificarlos como A. budini (CML 1738-1741, 1743-1751) y A. lutescens (CML 1734). Los valores morfométricos craneanos del primer grupo son claramente mayores (Tabla 2), presentando caracteres típicos de $A$. budini como caja craneana globosa, muescas cigomáticas estrechas y profundas, placa cigomática relativamente estrecha y molares hipsodontes.

\section{Akodon fumeus Thomas 1902}

Distribución en Argentina. Sector norte de Yungas, en Jujuy (Díaz 1999; Díaz \& Barquez 1999, 2007) y extremo norte de Salta, en el área de Los Toldos (este trabajo).

Distribución asociada a pastizales de neblina. En el ecotono entre pastizales de neblina y bosque montano superior. Los ejemplares fueron capturados en un área de pastizales dominados por Elionurus muticus y Paspalum notatum entremezclados con arbustos de Baccharis spp. y Stevia spp. y bosques de aliso y pino del cerro a $1700 \mathrm{~m}$.

Comentarios. Akodon fumeus fue mencionada para Argentina a partir de registros en áreas de selva montana de Yungas y pastizales de neblina asociados en Jujuy (Díaz 1999; Díaz \& Barquez 1999, 2007). Pardiñas et al. (2006), sin embargo, cuestionaron estas identificaciones. Estudios moleculares del gen que codifica para el citocromo $b$ han permitido confirmar la pertenencia de los ejemplares JPJ 1656 y JPJ 1670 a A. fumeus, con valores de divergencia génica menores a $1,5 \%$ en relación a ejemplares de esta especie provenientes de Bolivia. Numerosos rasgos de la morfología y morfometría craneana (Tabla 2) de los ejemplares obtenidos en el área de Los Toldos permiten distinguirlos de todas las especies con las que coexisten en el límite altitudinal inferior de los pastizales en el extremo norte de las Yungas argentinas. La fosa mesopterigoides ancha permite distinguirlos claramente de $A$. sylvanus y $A$. lutescens, mientras que la caja craneana menos globosa, la fosa mesopterigoides más estrecha y la menor hipsodoncia de sus molares los separan de ejemplares de $A$. budini. 
Tabla 2. Valores morfométricos para cuatro de las especies de Akodon presentes en el área de estudio. Se mencionan la procedencia de los ejemplares y/o la fuente bibliográfica de la que proviene la información. Para cada especie se brindan el tamaño de la muestra, el promedio y el desvío estandar. LTC: longitud total del cuerpo; LC: longitud de la cola; LP: longitud de la pata posterior (con uña); LO: longitud de la oreja; CIL: longitud condiloincisiva; RL: longitud del rostro; BB: ancho de la caja craneana; MTRL: longitud de la hilera molar superior; ZP: ancho de la placa cigomática.

\begin{tabular}{|c|c|c|c|c|c|c|c|c|}
\hline \multirow[b]{3}{*}{ Medidas } & \multicolumn{4}{|c|}{ Akodon budini } & \multicolumn{4}{|c|}{ Akodon fumeus } \\
\hline & \multicolumn{2}{|c|}{ El Duraznillo } & \multicolumn{2}{|c|}{ Jayat et al. $2007 \mathrm{~b}$} & \multicolumn{2}{|r|}{ Los Toldos } & \multicolumn{2}{|c|}{ Myers y Patton, 1989} \\
\hline & $\mathrm{n}$ & $\mathrm{X} \pm \mathrm{SD}$ & $\mathrm{n}$ & $\mathrm{X} \pm \mathrm{SD}$ & $\mathrm{n}$ & $\mathrm{X} \pm \mathrm{SD}$ & $\mathrm{n}$ & $\mathrm{X} \pm \mathrm{SD}$ \\
\hline LTC & 13 & $176 \pm 8.8$ & 8 & $183 \pm 15$ & 3 & $167 \pm 4$ & 32 & $171,2 \pm 12,64$ \\
\hline $\mathrm{LC}$ & 13 & $83 \pm 3.6$ & 9 & $73 \pm 10$ & 3 & $73 \pm 3$ & 32 & $76,2 \pm 5,67$ \\
\hline LP & - & - & 9 & $25 \pm 1$ & 3 & $23 \pm 1$ & 32 & $21,4 \pm 1,44$ \\
\hline LO & 13 & $19 \pm 1.8$ & 9 & $17 \pm 2$ & 3 & $16 \pm 0$ & 29 & $15,9 \pm 1,57$ \\
\hline CIL & 7 & $25.84 \pm 0.63$ & 8 & $26.05 \pm 1.13$ & 3 & $23.98 \pm 0.37$ & 35 & $23,48 \pm 0,85$ \\
\hline RL & 10 & $10.98 \pm 0.49$ & 7 & $10.71 \pm 0.32$ & 3 & $9.99 \pm 0.44$ & 35 & $9,78 \pm 0,36$ \\
\hline $\mathrm{BB}$ & 9 & $12.82 \pm 0.26$ & 8 & $12.79 \pm 0.24$ & 3 & $11.85 \pm 0.35$ & 33 & $11,68 \pm 0,21$ \\
\hline MTRL & 11 & $5.06 \pm 0.20$ & 8 & $4.93 \pm 0.15$ & 3 & $4.09 \pm 0.04$ & 34 & $4,10 \pm 0,26$ \\
\hline $\mathrm{ZP}$ & 10 & $2.51 \pm 0.16$ & 8 & $2.46 \pm 0.15$ & 3 & $2.13 \pm 0.11$ & 36 & $2.17 \pm 0.17$ \\
\hline
\end{tabular}

\begin{tabular}{|c|c|c|c|c|c|}
\hline \multicolumn{4}{|c|}{ Akodon lutescens } & \multirow{2}{*}{\multicolumn{2}{|c|}{$\begin{array}{l}\text { Akodon sylvanus } \\
\text { Jayat et al. } 2007 \mathrm{~b}\end{array}$}} \\
\hline \multicolumn{2}{|c|}{ El Duraznillo } & \multicolumn{2}{|c|}{ Myers et al., 1990} & & \\
\hline $\mathrm{n}$ & $\mathrm{X} \pm \mathrm{SD}$ & $\mathrm{n}$ & $\mathrm{X} \pm \mathrm{SD}$ & $\mathrm{n}$ & $\mathrm{X} \pm \mathrm{SD}$ \\
\hline 1 & 139 & 34 & $148 \pm 13,18$ & 54 & $176 \pm 11.17$ \\
\hline 1 & 62 & 34 & $60,6 \pm 4,68$ & 54 & $77 \pm 5.70$ \\
\hline- & - & 34 & $18,7 \pm 0,75$ & 53 & $25 \pm 1$ \\
\hline 1 & 12 & 23 & $14,0 \pm 1,73$ & 54 & $17 \pm 1$ \\
\hline 1 & 20.7 & 34 & $20,65 \pm 0,94$ & 53 & $24.66 \pm 0.85$ \\
\hline- & - & 34 & $8,15 \pm 0,52$ & 54 & $10.23 \pm 0.36$ \\
\hline 1 & 10.7 & 34 & $10,53 \pm 0,29$ & 54 & $12.09 \pm 0.27$ \\
\hline 1 & 3.8 & 35 & $3,59 \pm 0,11$ & 55 & $4.34 \pm 0.15$ \\
\hline 1 & 1.9 & 35 & $1.99 \pm 0.15$ & 55 & $2.37 \pm 0.20$ \\
\hline
\end{tabular}

\section{Necromys amoenus (Thomas 1900)}

Distribución en Argentina. Recientemente capturada en Salta, cerca de la frontera con Bolivia, a $3100 \mathrm{~m}$ (Jayat et al. 2006).

Distribución asociada a pastizales de neblina. En el límite superior de los pastizales, en áreas de ecotono con ambientes altoandinos. La zona de captura presenta matas dispersas de gramíneas dispuestas sobre un sustrato rocoso (Fig. 2 b).

Comentarios. Extremadamente rara en su área de distribución, con escasos registros para Perú y Bolivia (Anderson \& Olds 1989, Salazar-Bravo et al. 2002). La cita argentina constituye el registro más austral para la especie (Jayat et al. 2006). 


\section{Necromys sp.}

Distribución en Argentina. Un registro para Tucumán en pastizales asociados a Yungas y Chaco (Capllonch et al. 1997, como Bolomys orbus).

Distribución asociada a pastizales de neblina. Registrada junto a Akodon aliquantulus, en el límite altitudinal inferior de los pastizales.

Comentarios. El confuso contexto taxonómico del género y el escaso material examinado impiden una determinación específica confiable.

\section{Oxymycterus sp.}

Distribución en Argentina. Conocida para cuatro localidades de Tucumán, en áreas de Yungas entre 800 y $2400 \mathrm{~m}$ (Jayat et al. en prep.).

Distribución asociada a pastizales de neblina. Áreas de ecotono con el bosque montano, en quebradas húmedas cubiertas de alisos y pastizales dominados por Festuca, Deyeuxia y Stipa (Fig. 2 c).

Comentarios. Esta forma representa una nueva especie en proceso de descripción (Jayat et al. en prep.). El material de La Angostura fue citado por Ortiz \& Pardiñas (2001) como Oxymycterus cf. $O$. paramensis. Sin embargo, la estructura simplificada de sus molares y detalles de la mandíbula indican su pertenencia a esta nueva especie.

\section{Tribu Phyllotini Vorontsov 1959 \\ Calomys fecundus (Thomas 1926)}

Distribución en Argentina. Santiago del Estero, Tucumán (Salazar-Bravo et al. 2002, Dragoo et al. 2003).

Distribución asociada a pastizales de neblina. Sólo para los límites inferior y superior de los pastizales en el valle de Tafí, Tucumán, a 1900 y 3000 m respectivamente (Olds 1988, como C. boliviae; Ortiz \& Pardiñas 2001, como C. venustus).

Comentarios. Las formas grandes de Calomys en el noroeste argentino fueron tratadas como C. callosus (e.g. Ojeda \& Mares 1989, Capllonch et al. 1997), C. venustus (e.g. Mares et al. 1997, Díaz et al. 2000, Ortiz \& Pardiñas 2001, Díaz \& Barquez,2007), C. fecundus (e.g. Salazar-Bravo et al. 2002, Dragoo et al. 2003) y C. boliviae (e.g. Díaz 1999, Díaz et al. 2006, Díaz \& Barquez 2007). Sobre la base de análisis moleculares, Salazar-Bravo et al. (2002) y Dragoo et al. (2003) asignaron especímenes de Tucumán y oeste de Santiago del Estero a C. fecundus, postura adoptada en este trabajo. No obstante, véanse los comentarios de Salazar-Bravo et al. (2003) acerca de la posibilidad de que C. boliviae sea sinónimo senior de C. fecundus.

\section{Graomys edithae Thomas 1919}

Distribución en Argentina. Sólo mencionada para su localidad tipo y una localidad adicional en el sur de Catamarca (Thomas 1919, Hershkovitz 1962, Mares et al. 1997).

Distribución asociada a pastizales de neblina. El área de Otro Cerro corresponde a una transición entre pastizales y ambientes semiáridos de altura con escasa cobertura vegetal y abundancia de afloramientos rocosos.

Comentarios. Aunque válida para la mayoría de los autores, su estatus taxonómico fue considerado incierto (Braun 1993, Galliari et al. 1996, Mares et al. 1997, Musser \& Carleton 2005, Díaz et al. 2006). La postura seguida en este trabajo sigue este consenso habida cuenta de la ausencia de revisiones taxonómicas y de colectas de especímenes adicionales en la localidad tipo y sus alrededores. 


\section{Graomys griseoflavus (Waterhouse 1837)}

Distribución en Argentina. Sólo ausente en Corrientes, Entre Ríos, Misiones, Santa Fe y Tierra del Fuego (Díaz et al. 2006), habitando desde la estepa patagónica, el Espinal y el Chaco hasta el Monte y la Prepuna (Pearson 1958, Hershkovitz 1962, Mares et al. 1997, Díaz 1999, Díaz et al. 2000, Pardiñas et al. 2003, Díaz et al. 2006, Díaz \& Barquez 2007).

Distribución asociada a pastizales de neblina. Por el momento sólo registrada en el extremo sur del área de estudio, en zonas ecotonales con ambientes de escasa cobertura vegetal como la Prepuna y áreas de vegetación altoandina, a 3000 m o más.

Comentarios. Los registros aquí reportados fueron tomados de fuentes bibliográficas (Thomas 1919, Hershkovitz 1962, Mares et al. 1997). La correcta asignación de los ejemplares que sustentan estas citas depende de estudios taxonómicos más detallados sobre el estatus de las formas nominales mencionadas para el noroeste de Argentina (e.g. cachinus, centralis, griseoflavus, medius).

\section{Phyllotis anitae (Jayat et al. 2007a, D’Elía, Pardiñas \& Namen 2007)}

Distribución en Argentina. Sólo para la localidad tipo en Tucumán (Jayat et al. 2007).

Distribución asociada a pastizales de neblina. Registrada únicamente en el ecotono entre pastizales y bosques montanos a $2400 \mathrm{~m}$, en un ambiente de bosques de aliso dispuestos en quebradas húmedas, con un sotobosque de gramíneas, helechos y arbustos (Fig. 2 c).

Comentarios. Extremadamente rara en su área de captura y probablemente endémica del extremo sur de Yungas (Jayat et al. 2007a).

\section{Phyllotis caprinus Pearson 1958}

Distribución en Argentina. Principalmente en ambientes de Prepuna y Puna en Jujuy (Pearson 1958, Díaz 1999, Díaz \& Barquez 2007) y en Monte en Salta (Díaz et al. 2000).

Distribución asociada a pastizales de neblina. En la transición entre pastizales y Prepuna, en ambientes con escasa cobertura de gramíneas y numerosas especies de cactus de pequeño porte y plantas en cojín, sobre un sustrato rocoso.

Comentarios. La comunidad de micromamíferos registrada en el área de captura refleja claramente el ecotono Yungas-Prepuna, en la que coexisten especies típicas de bosques (e.g. Thylamys sponsorius, Akodon lutescens) junto a formas comunes en ambientes abiertos de altura (e.g. Thylamys pallidior, Calomys musculinus).

\section{Phyllotis xanthopygus (Waterhouse 1837)}

Distribución en Argentina. Amplia distribución, por el oeste desde Jujuy hasta Santa Cruz (Steppan 1998, Jayat et al. 2006, Díaz et al. 2006, Díaz \& Barquez 2007), en ambientes áridos y semiáridos como la estepa patagónica, Prepuna, Monte, Puna y Chaco Seco (Kramer et al. 1999, Jayat et al. 2006).

Distribución asociada a pastizales de neblina. Todo el gradiente latitudinal de los pastizales de neblina en el noroeste argentino. La mayor parte de sus registros en áreas de transición con ambientes de escasa cobertura vegetal y abundantes afloramientos rocosos a más de $3000 \mathrm{~m}$. También registrado en altitudes menores en el ecotono entre pastizales y ambientes xéricos como Chaco Serrano.

Comentarios. La cita de Heinonen \& Bosso (1994) para el bosque montano superior en Duraznillar, un ambiente húmedo de pastizales de neblina completamente atípico para la especie, debe ser confirmada. 
Aunque los ejemplares referidos por estos autores no pudieron ser examinados, especímenes adicionales de la misma (CML 1724, 1725) fueron asignados por Díaz (1999), Díaz \& Barquez (2007) y en el presente trabajo, a $P$. osilae. Además, ejemplares de Cerro Hermoso (MACN 19521-19540), próximos a Duraznillar, identificados como P.xanthopygus por Heinonen \& Bosso (1994) (P. darwini en ese trabajo), corresponden también a $P$. osilae, presentando coloración oscura, pelaje corto, vibrisas poco abundantes y fosetas posteropalatales pequeñas situadas detrás del borde anterior de la fosa mesopterigoides. Ejemplares de La Angostura asignados por Ortiz \& Pardiñas (2001) a P. cf. P. xanthopygus son reidentificados aquí como $P$. osilae.

\section{Tapecomys wolfssohni (Thomas 1902)}

Distribución en Argentina. Estudios recientes confirman su presencia en Jujuy y Salta, en Yungas y áreas ecotonales de pastizales de neblina (Jayat et al. 2006).

Distribución asociada a pastizales de neblina. El ambiente en Santa Victoria corresponde a un ecotono entre pastizales y ambientes de tipo prepuneño.

Comentarios. T. wolffsohni no ha sido registrada en nuestras campañas a pesar de intensos muestreos en el área de estudio. Originalmente descripta para el género Phyllotis, esta forma nominal ha sido incluida recientemente en Tapecomys por Steppan et al. (2007).

\section{Tribu Reithrodontini Vorontsov 1959}

\section{Reithrodon auritus (Fischer 1814)}

Distribución en Argentina. Extensa geonemia desde Tierra del Fuego hasta el noroeste, incluyendo Mendoza y las regiones patagónica y pampeana. En el noroeste es conocida para pocas localidades aisladas en Catamarca, Jujuy y Tucumán, en áreas abiertas de pastizales (Pardiñas \& Galliari 2001, Jayat et al. 2006).

Distribución asociada a pastizales de neblina. Sólo registrada en el extremo sur del área de estudio, en zonas ecotonales a $3000 \mathrm{~m}$ en donde predominan el suelo desnudo y afloramientos rocosos.

Comentarios. El registro de El Espinillo corresponde a material recuperado de egagrópilas de lechuza (Jayat et al. 2006).

\section{Especies de presencia dudosa \\ Orden Rodentia Bowdich 1821 \\ Familia Cricetidae Rochebrune 1883 \\ Subfamilia Sigmodontinae Wagner 1843 \\ Tribu Oryzomyini Vorontsov 1959 \\ Oligoryzomys chacoensis (Myers \& Carleton 1981)}

Comentarios. Registrada en Chaco, Formosa, Jujuy y Salta para ambientes del Chaco Húmedo, Chaco Seco y zonas de transición con Yungas por debajo de $800 \mathrm{~m}$ (Heinonen \& Bosso 1994, Díaz 1999, Díaz et al. 2000, Gil \& Heinonen 2003, Cirignoli et al. 2006, Díaz $\&$ Barquez 2007). Existe un único registro para pastizales de neblina en transición con Prepuna a 2200 m (Díaz 1999, Díaz \& Barquez 2007), ambiente atípico para la especie, por lo que su presencia en estos pastizales necesita ser confirmada. Aunque en los últimos años se han colectado numerosos ejemplares en sectores pedemontanos de Yungas, la especie no fue registrada en los pastizales de neblina, a pesar de un considerable esfuerzo de muestreo (más de 100 ejemplares de Oligoryzomys para 19 localidades). 


\section{Tribu Phyllotini Vorontsov 1959 \\ Calomys laucha (Fischer 1814)}

Comentarios. Mencionada, a partir de un único ejemplar de Tucumán, para un ambiente de ecotono entre pastizales y bosque montano de Yungas (Hershkovitz 1962). Calomys laucha es típica de tierras bajas asociadas al Chaco Húmedo, Espinal y región pampeana (Díaz et al. 2006), por lo que su presencia en pastizales de neblina debe ser considerada dudosa. No se capturaron ejemplares en el área de estudio y probablemente el único espécimen registrado corresponda a C. musculinus.

\section{Eligmodontia moreni Thomas 1896}

Comentarios. La localidad referida por Mares et al. (1997) corresponde a un ecotono entre pastizales de neblina y Prepuna, pero se encuentra situada en proximidades de áreas con arenales, ambiente característico para el género y completamente ausentes en el área de estudio. Además, la cita representa el único registro de E. moreni para un ambiente asociado a estos pastizales.

\section{DISCUSIÓN}

Hasta las recientes contribuciones de Jayat \& Pacheco (2006) y Jayat et al. (2006), la diversidad de sigmodontinos en los pastizales de neblina del noroeste argentino y sus ecotonos era conocida por menos de 100 registros puntuales y sólo para 27 localidades, la mayoría de éstas agrupadas en la zona de León y las cumbres de Calilegua, en Jujuy, y diversas localidades en el Valle de Tafí y extremo sur de la sierra del Aconquija, en Tucumán. Estos registros, basados sobre escasos ejemplares, fueron en su mayoría obtenidos con anterioridad a la década de 1990. La escasez de registros de sigmodontinos de pastizales de neblina para la provincia de Salta era notoria, con apenas 2 localidades relevadas (Díaz et al. 2000, Ortiz et al. 2000).

Sobre la base de 1390 especímenes colectados entre 1999 y 2006, en este trabajo se reporta por primera vez, y en forma integral, la composición de la comunidad de sigmodontinos de los pastizales de neblina y sus ecotonos en el noroeste argentino. Estos resultados se reportan sobre la base de 71 localidades distribuidas a lo largo de todo el gradiente latitudinal y altitudinal de estos pastizales en Argentina. Estas localidades incluyen además áreas de pastizales ubicadas sobre sistemas de sierras aislados como la Sierra del Centinela (Jujuy), Cumbres de Medina (Tucumán) y Sierra de Ancasti (Catamarca), previamente no relevadas.

La suma total de fuentes de información ha permitido registrar 34 especies de sigmodontinos para este ambiente y áreas ecotonales asociadas al mismo. Entre éstas, se reconocen 15 especies con al menos un registro en pastizales puros ( 2 de ellas exclusivas de los pastizales de neblina y sus ecotonos), 16 sólo están presentes en áreas ecotonales y 3 se consideran de presencia dudosa.

Algunas de las especies (Abrothrix andinus, Oligoryzomys chacoensis, Calomys laucha, Eligmodontia moreni, Graomys edithae y G. griseoflavus) fueron tomadas de la bibliografía y no pudieron ser documentadas mediante captura o revisión de 
colecciones. Todas éstas han sido citadas sólo para áreas ecotonales y presentan $1 \mathrm{o}$ 2 registros en el área de estudio. De ellas, O. chacoensis, C. laucha y E. moreni probablemente deban ser descartadas para este ambiente, en tanto que el resto de las especies, de estar presentes, sólo lo harían en áreas marginales. El estudio de colecciones permitió adicionar, además, a Tapecomys wolffsohni, recientemente documentado para este ambiente en un área de transición con la prepuna (Jayat et al. 2006).

Entre las especies capturadas, Akodon boliviensis, A. sylvanus, Necromys lasiurus, Oxymycterus sp. y Phyllotis anitae fueron recientemente registradas para pastizales de neblina o sus ecotonos en Argentina (Jayat et al. 2006, 2007a, en prep.). De ellas, Oxymycterus sp. y Phyllotis anitae, especies nuevas para la ciencia, sólo están presentes en el área de transición con el bosque montano de Yungas (Jayat et al. $2007 \mathrm{a}$, en prep.).

Sólo dos de las especies registradas (Necromys lactens y Phyllotis osilae) pueden considerarse habitantes característicos de los pastizales de neblina. Aunque también capturadas en áreas ecotonales con ambientes abiertos de altura y con bosques de Yungas, estas especies han sido documentadas en la mayoría de las localidades de pastizales relevadas, ocupando todo el gradiente altitudinal y latitudinal (Tabla 1 y Figura 3). Las escasas menciones para otros ambientes fueron consideradas dudosas y discutidas ampliamente en Jayat \& Pacheco (2006). Entre las especies que cuentan con al menos un registro en pastizales de neblina puros, Akodon boliviensis, Calomys lepidus y Neotomys ebriosus sólo se encuentran en el límite altitudinal superior, desde $2400 \mathrm{~m}$, mientras que $A$. sylvanus, Necromys lasiurus, Oligoryzomys cf. $O$. flavescens y Oligoryzomys sp. están principalmente asociadas al límite altitudinal inferior, por debajo de $2600 \mathrm{~m}$. Se encuentran, además, numerosas especies que se distribuyen en todo el gradiente altitudinal de los pastizales, tales como Akodon simulator, A. spegazzinii, Oxymycterus paramensis, Calomys musculinus y Andinomys edax (Figura 3a). El resto de las especies muestran un menor grado de afinidad por los pastizales, alcanzando los mismos sólo en sectores ecotonales y sin registros en pastizales de neblina puros. Especies sólo documentadas en el ecotono entre pastizales y ambientes abiertos de altura incluyen a Necromys amoenus, Graomys edithae, G. griseoflavus, Phyllotis caprinus, Tapecomys wolffsohni y Reithrodon auritus. Este es también el caso de Phyllotis xanthopygus y Calomys fecundus, documentadas además por debajo de $2000 \mathrm{~m}$ en ecotono con ambientes boscosos. En tanto, los registros para Abrothrix illuteus, Akodon aliquantulus, A. budini, A. fumeus, Necromys sp., Oxymycterus sp. y Phyllotis anitae provienen sólo de ambientes de transición con áreas boscosas (Tabla 1).

En cuanto al patrón latitudinal, la comunidad de sigmodontinos de pastizales de neblina no muestra una caída de especies de norte a sur, sino más bien un reemplazo, con Akodon boliviensis, A. budini, A. fumeus, A. sylvanus, Necromys amoenus, 


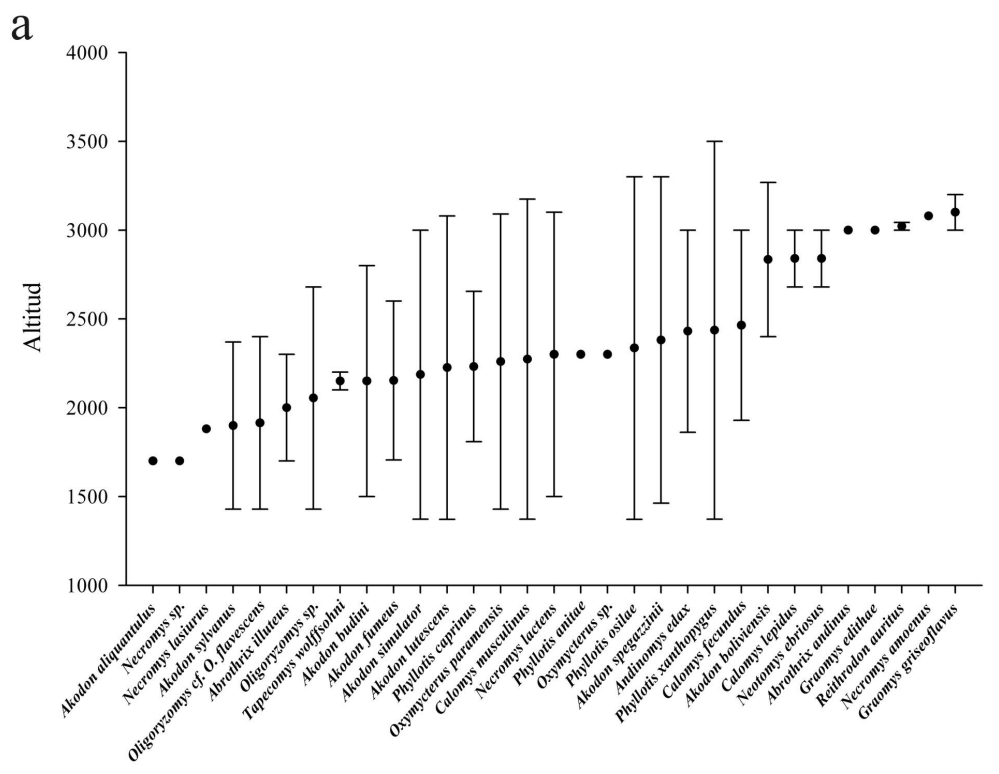

b

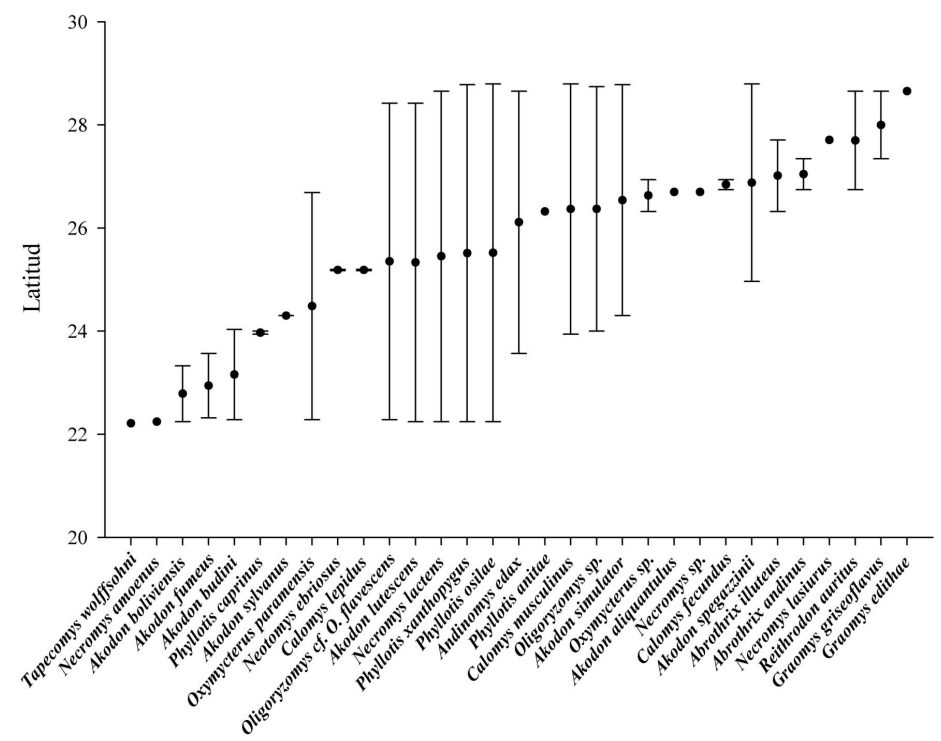

Figura 3. Rangos altitudinal (a) y latitudinal (b) conocidos para las especies de sigmodontinos en los pastizales de neblina. El punto indica el valor altitudinal/latitudinal medio en la distribución o el único punto conocido. En el caso del rango altitudinal de Calomys fecundus y Phyllotis xanthopygus, que fueran sólo registradas en los extremos superior e inferior de los pastizales, el gráfico muestra una distribución continua entre puntos. 
Phyllotis caprinus y Tapecomys wolffsohni restringidas al sector norte y Abrothrix andinus, A. illuteus, Akodon aliquantulus, Calomys fecundus, Graomys edithae, G. griseoflavus, Necromys lasiurus, Necromys sp., Oxymycterus sp., Reithrodon auritus y Phyllotis anitae distribuidas sólo en el sector sur. Especies sólo registradas en el sector central incluyen a Calomys lepidus y Neotomys ebriosus mientras que Akodon lutescens, A. simulator, A. spegazzinii, Andinomys edax, Calomys musculinus, Necromys lactens, Oligoryzomys cf. O. flavescens, Oligoryzomys sp., Oxymycterus paramensis, Phyllotis osilae y Phyllotis xanthopygus están todas relativamente extendidas en el gradiente latitudinal (Figura 3b).

La fauna de sigmodontinos de pastizales de neblina y sus ecotonos está dominada por representantes de las tribus Akodontini y Phyllotini, constituyendo en conjunto casi el $80 \%$ de las especies registradas. El género Akodon es el más diverso en el área de estudio, con 8 especies documentadas, seguido de Necromys y Phyllotis con 4 especies cada una. Las tribus Oryzomyini y Abrotrichinos están pobremente representadas, con sólo 2 especies cada una. Completan el ensamble un Reithrodontini y dos especies incertae sedis.

Aunque los pastizales de neblina puros ocupan una superficie reducida, limitada a una estrecha faja altitudinal, su riqueza en especies de sigmodontinos es elevada y comparable a la de la mayoría de las unidades fitogeográficas del noroeste, a excepción de las áreas boscosas de Yungas. Los valores de riqueza de especies son similares a los de la Puna, el Monte y el Chaco y superan a la región altoandina. Más aún, la riqueza específica registrada en los pastizales de neblina supera a la de los pisos altitudinales boscosos de Yungas cuando se consideran las especies presentes en las áreas ecotonales de estos dos ambientes. Esta alta riqueza no es el resultado de la presencia de especies exclusivas de los pastizales sino de la reunión, en esta estrecha franja, de taxones ampliamente distribuidos en ambientes circundantes.

Si bien este trabajo constituye un avance en el conocimiento de la diversidad de roedores sigmodontinos de los pastizales de neblina, el panorama dista de ser completo. Estudios recientes en el área, que incluyen la descripción de nuevas especies (Jayat et al. 2007a, en prep.), la adición de numerosas formas conocidas para otros ambientes (Jayat et al. 2006) y la existencia de especímenes cuya asignación específica es provisoria justifican esta afirmación. En este contexto, muestreos adicionales y estudios taxonómicos más profundos ampliarán el conocimiento de la diversidad real de sigmodontinos en este ambiente, lo que constituye un requisito fundamental para la comprensión de la evolución de estas comunidades y su valoración en un contexto ecológico y de conservación.

Agradecimientos: O. Díaz, M. E. Fanjul, L. Ferre, I. Ferro, K. García, D. García López, D. Juri, Z. Juri, E. Martín, M. E. Mosca, G. Námen, U. Pardiñas, M. Quoirín, V. Deraco, S. Sabate, J. Torres 
y W. Villafañe (Almita) colaboraron en las tareas de campo. Un agradecimiento especial para la Familia Mosca, la Familia Usandivaras y a Cristina Arfelli que gentilmente cedieron sus casas en Campo Quijano, Medina y Bárcena como base para alguno de los muestreos. M. Rougés, H. R. Grau y A. Echevarría facilitaron equipo de campo imprescindible para este trabajo. I. Gasparri fue el principal responsable de la confección del mapa de los pastizales de neblina. Agradecemos también a los curadores de las colecciones estudiadas que gentilmente permitieron el acceso a los materiales depositados en las mismas. Los comentarios y sugerencias de U. Pardiñas, P. Teta y dos revisores anónimos mejoraron la calidad del manuscrito inicial. El mapa de distribución fue realizado por el sistema de información geográfico ambiental (SIGA) de la Fundación Proyungas. Este trabajo fue parcialmente solventado mediante una beca de formación de postgrado otorgada por el CONICET y un subsidio otorgado por la Fundación ProYungas a uno de los autores (J. P. Jayat) y se llevó a cabo con el apoyo institucional del Laboratorio de Investigaciones Ecológicas de las Yungas (LIEY) y la Cátedra de Paleontología II de la Facultad de Ciencias Naturales e Inst. M. Lillo, UNT.

\section{LITERATURA CITADA}

Abdala, F. \& M.M. Díaz. 2000. Anatomía craneana de Akodon albiventer (Rodentia, Muridae, Sigmodontinae). Iheringia, serie Zoologia. 88:33-50.

Aceñolaza, F.G. \& A. Toselli. 1981. Geología del Noroeste Argentino. Universidad Nacional de Tucumán, Argentina.

Barquez, R.M. 1976. Nuevo registro de distribución de Oxymycterus paramensis (Mammalia, Rodentia, Cricetidae). Neotropica. 22:115.

. 1983. La distribución de Neotomys ebriosus Thomas en la Argentina y su presencia en la provincia de San Juan (Mammalia, Rodentia, Cricetidae). Historia Natural, Argentina. 3:189-191.

Barquez, R.M, M.M. Díaz \& R.A. Ojeda. 2006b. Mamíferos de Argentina: sistemática y distribución. Sociedad Argentina para el Estudio de los Mamíferos (SAREM), Mendoza.

Barquez, R.M., L.I. Ferro \& M.S. Sánchez. 2006a. Tapecomys primus (Rodentia: Cricetidae), nuevo género y especie para la Argentina. Mastozoología Neotropical. 13:117-121.

Barquez, R.M., M.A. Mares \& R.A. Ojeda. 1991. Mamíferos de Tucumán. Oklahoma Museum of Natural History, Norman.

Barquez, R.M., D.F. Williams, M.A. Mares \& H.H. Genoways. 1980. Karyology and morphometrics of three species of Akodon (Mammalia: Muridae) from northwestern Argentina. Annals of the Carnegie Museum. 49:379-403.

Bianchi, N.O., O.A. Reig, O.J. Molina \& F.N. Dulout. 1971. Cytogenetics of the South American akodont rodents (Cricetidae). I. A progress report of Argentinian and Venezuelan forms. Evolution. 25:724-736.

Brown, A.D. \& H.R. Grau. 1993. La naturaleza y el hombre en las selvas de montaña. Proyecto GTZ - Desarrollo agroforestal en las comunidades rurales del noroeste argentino.

Burkart, R., N. Bárbaro, R.O. Sánchez \& D.A. Gómez. 1999. Eco-regiones de la Argentina. Administración de Parques Nacionales y Programa de Desarrollo Institucional y Ambiental, Buenos Aires.

Bustos, M. 1995. Diversidad de micromamíferos terrestres durante una sucesión secundaria de Selva Montana. Pp. 115-122. In: A.D. Brown y H.R. Grau (Eds). Investigación, conservación y desarrollo en selvas subtropicales de montaña. Laboratorio de Investigaciones Ecológicas de las Yungas, Universidad Nacional de Tucumán.

Cabrera, A. 1926. Dos roedores nuevos de las montañas de Catamarca. Revista Chilena de Historia Natural. 30:319-321. 
Cabrera, A.L. 1976. Regiones Fitogeográficas Argentinas. Editorial ACME, Buenos Aires.

Capllonch, P., A.G. Autino, M.M. Díaz, R.M. Barquez \& M. Goytia. 1997. Los mamíferos del Parque Biológico Sierra de San Javier, Tucumán, Argentina: Observaciones sobre su sistemática y distribución. Mastozoología Neotropical. 4:49-71.

Carleton, M.D. \& G.G. Musser. 1989. Systematic studies of oryzomyine rodents (Muridae, Sigmodontinae): a synopsis of Microryzomys. Bulletin of the American Museum of Natural History. 191:1-83.

Cirignoli, S., P. Teta, U.F.J. Pardiñas \& G. D'Elía. 2006. Oryzomyini Vorontzov, 1959. Pp. 166-175. In: R.M. Barquez, M.M. Díaz y R. Ojeda (Eds). Mamíferos de Argentina: sistemática y distribución. Sociedad Argentina para el Estudio de los Mamíferos (SAREM), Mendoza.

Dalby, P.L. \& M.A. Mares. 1974. Notes on the distribution of the Coney Rat, Reithrodon auritus, in Northwestern Argentina. American Midland Naturalist. 92:205-206.

D'Elía, G., P. Teta \& U.F.J. Pardiñas. 2006. Incertae sedis. Pp. 197-202. In: R.M. Barquez, M.M. Díaz y R. Ojeda (Eds). Mamíferos de Argentina: sistemática y distribución. Sociedad Argentina para el Estudio de los Mamíferos (SAREM), Mendoza.

Díaz, M.M. 1999. Mamíferos de la Provincia de Jujuy: Sistemática, distribución y ecología. Tesis doctoral, Facultad de Ciencias Naturales e Instituto Miguel Lillo, Universidad Nacional de Tucumán, Argentina.

Díaz, M.M. \& R.M. Barquez. 1999. Contributions to the knowledge of the mammals of Jujuy Province, Argentina. Southwestern Naturalist. 44:324-333.

2007. The Wild Mammals of Jujuy Province, Argentina: Systematics and Distribution. Pp. 417578. In: D.A. Kelt, E.P. Lessa, J. Salazar-Bravo y J.L. Patton (Eds). The Quintessential Naturalist: Honoring the Life and Legacy of Oliver P. Pearson. University of California Publications in Zoology 134.

Díaz, M.M., R.M. Barquez, J.K. Braun \& M.A. Mares. 1999. A new species of Akodon (Muridae: Sigmodontinae) from northwestern Argentina. Journal of Mammalogy. 80:786-798.

Díaz, M.M., J.K. Braun, M.A. Mares \& R.M. Barquez. 2000. An update of the taxonomy, systematics, and distribution of the mammals of Salta province, Argentina. Occasional Papers of the Sam Noble Oklahoma Museum of Natural History, University of Oklahoma. 10:1-52.

Díaz, M.M., P. Teta, U.F.J. Pardiñas \& R.M. Barquez. 2006. Phyllotini Vorontzov, 1959. Pp. 175189. In: R.M. Barquez, M.M. Díaz y R. Ojeda (Eds). Mamíferos de Argentina: sistemática y distribución. Sociedad Argentina para el Estudio de los Mamíferos (SAREM), Mendoza.

Dragoo, J.W., J. Salazar-Bravo, L.J. Layne \& T.L. Yates. 2002. Relationships within the Calomys callosus species group based on amplified fragment length polymorphisms. Biochemical Systematics and Ecology. 31:703-713.

Gil, G. \& S. Heinonen Fortabat. 2003. Lista comentada de los mamíferos del Parque Nacional Baritú (Salta, Argentina). Acta Zoológica Lilloana. 47:117-135.

Grau, H.R. \& T.T. Veblen. 2000. Rainfall variability, fire and vegetation dynamics in neotropical montane ecosystem in north-western Argentina. Journal of Biogeography. 27:1107-1121.

Heinonen Fortabat, S. \& A. Bosso. 1994. Nuevos aportes para el conocimiento de la mastofauna del Parque Nacional Calilegua (Provincia de Jujuy, Argentina). Mastozoología Neotropical. 1:51-60.

Hershkovitz, P. 1962. Evolution of Neotropical cricetine rodents (Muridae) with special reference to the phyllotine group. Fieldiana Zoology. 46:1-524.

Jayat, J.P., G. D'Elia, U.F.J. Pardiñas \& J.G. Namen. 2007a. A new species of Phyllotis (Rodentia, Cricetidae, Sigmodontine) from the upper montane forest of the Yungas of northwestern Argentina. Pp. 775-798. In: D.A. Kelt, E.P. Lessa, J. Salazar-Bravo y J.L. Patton (Eds). The Quintessential Naturalist: Honoring the Life and Legacy of Oliver P. Pearson. University of California Publications in Zoology, Davis. 
Jayat, J.P., P.E. Ortiz, U.F.J. Pardiñas \& G. D'Elía. 2007b. Redescripción y posición filogenética del ratón selvático (Akodon sylvanus: Rodentia: Cricetidae). Mastozoología Neotropical. 14:201-225.

Jayat, J.P., P.E. Ortiz, P. Teta, U.F.J. Pardiñas \& G. D'Elía. 2006. Nuevas localidades argentinas para algunos roedores sigmodontinos (Rodentia: Cricetidae). Mastozoología Neotropical. 13:51-67.

Jayat, J.P. \& S. Pacheco. 2006. Distribución de Necromys lactens y Phyllotis osilae (Rodentia: Cricetidae: Sigmodontinae) en el noroeste argentino: modelos predictivos basados en el concepto de nicho ecológico. Mastozoología Neotropical. 13:69-88.

Kajon, A.E., O.A. Scaglia, C. Horgan, C. Velazquez, M.S. Merani \& O.A. Reig. 1984. Tres nuevos cariotipos de la tribu Akodontini (Rodentia, Cricetidae). Revista del Museo Argentino de Ciencias Naturales “Bernardino Rivadavia”, Zoología. 13(48):461-469.

Mares, M.A. 1977. Water balance and other ecological observations on three species of Phyllotis in Northwestern Argentina. Journal of Mammalogy. 58:514-520.

Mares, M.A, R.A. Ojeda \& R.M. Barquez. 1989. Guide to the mammals of Salta Province, Argentina - Guía de los mamiferos de la Provincia de Salta, Argentina. University of Oklahoma Press, Norman.

Mares, M.A., R.A. Ojeda, J.K. Braun \& R.M. Barquez. 1997. Systematics, distribution, and ecology of the mammals of Catamarca Province, Argentina. Pp. 89-141. In: T.L. Yates, W.L. Gannon y D.E. Wilson (Eds). Life among the muses: Papers in honor of James S. Findley. Museum of Southwestern Biology, University of New México, Albuquerque.

Mares, M.A., R.A. Ojeda \& M.P. Kosco. 1981. Observations on the distribution and ecology of the mammals of Salta Province, Argentina. Annals of the Carnegie Museum. 50:151-206.

Massoia, E. 1971. Akodon varius toba Thomas en la República Argentina (Mammalia-Rodentia-Cricetidae). Revista de Investigaciones Agropecuarias, INTA (Instituto Nacional de Tecnología Agropecuaria), Patología Animal. 8:123-129.

Massoia, E. 1976. Mammalia. Pp. 1-128. In: R. Ringuelet (Ed). Fauna de agua dulce de la República Argentina. FECIC, Buenos Aires.

Musser, G.G. \& M.D. Carleton. 2005. Superfamily Muroidea. Pp. 894-1531. In: D. E. Wilson y D. M. Reeder (Eds). Mammal Species of the World: A taxonomic and geographic reference. Third edition. The Johns Hopkins University Press, Baltimore.

Myers, P. 1989. A preliminary revision of the varius group of Akodon (A. dayi, dolores, molinae, neocenus, simulator, toba, and varius). Pp. 5-54. In: K.H. Redford y J.F. Eisenberg (Eds). Advances in Neotropical Mammalogy. The Sandhill Crane Press, Inc. Gainesville, Florida.

Myers, P., J.L. Patton \& M.F. Smith. 1990. A review of the boliviensis group of Akodon (Muridae: Sigmodontinae) with emphasis on Perú and Bolivia. Miscelaneous Publications, Museum of Zoology, University of Michigan. 177:1-89.

Ojeda, R.A. \& M.A. Mares. 1989. A biogeographic analysis of the mammals of Salta Province, Argentina. Special Publications of the Texas Tech University. 27:1-66.

Olds, N. 1988. A revision of the genus Calomys (Rodentia:Muridae). Ph. D. dissertation, University of New York, New York.

Olrog, C.C. 1979. Los mamíferos de la selva húmeda, Cerro Calilegua, Jujuy. Acta Zoológica Lilloana. 33:9-14.

Ortiz, P.E., S. Cirignoli, D.H. Podesta \& U.F.J. Pardiñas. 2000. New records of sigmodontine rodents (Mammalia: Muridae) from high-andean localities of northwestern Argentina. Biogeographica. 76:133-140.

Ortiz, P.E. \& U.F.J. Pardiñas. 2001. Sigmodontinos (Mammalia, Rodentia) del Pleistoceno tardío del Valle de Tafí (Tucumán, Argentina): taxonomía, tafonomía y reconstrucción paleoambiental. Ameghiniana. 38:3-26. 
Pardiñas, U.F.J., G. D'Elía, P. Teta, P.E. Ortiz, J.P. Jayat \& S. Cirignoli. 2006. Akodontini Vorontzov, 1959 (sensu D’Elía, 2003). Pp. 146-166. In: R.M. Barquez, M.M. Díaz y R. Ojeda (Eds). Mamíferos de Argentina: sistemática y distribución. Sociedad Argentina para el Estudio de los Mamíferos (SAREM), Mendoza.

Pardiñas, U.F.J. \& C.A. Galliari. 2001. Reithrodon auritus. Mammalian species. 664:1-8.

Pardiñas, U.F.J. \& P.E. Ortiz. 2001. Neotomys ebriosus, an enigmatic South American Rodent (Muridae, Sigmodontinae): its fossil record and present distribution in Argentina. Mammalia. 65:244-250.

Pearson, O.P. 1958. A taxonomic revision of the rodent Genus Phyllotis. University of California Publications in Zoology. 56:391-496.

Rivera, P.C., R.E. González Ittig, H.J. Rossi Fraire, S. Levis \& C.N. Gardenal. 2007. Molecular identification and phylogenetic relationships among the species of the genus Oligoryzomys (Rodentia, Cricetidae) presents in Argentina, putative reservoirs of hantaviruses. Zoologica Scripta. 36: 231-239.

Salazar-Bravo, J., J.W. Dragoo, M.D. Bowen, C.J. Peters, T.G. Ksiazek \& T.L. Yates. 2002. Natural nidality in Bolivian hemorragic fever and the systematics of the reservoir species. Infection, Genetics and Evolution. 1:191-199.

Steppan, S. 1995. Revision of the tribe Phyllotini (Rodentia: Sigmodontinae), with a phylogenetic hypothesis for the Sigmodontinae. Fieldiana, Zoology, new series. 80:1-112. . 1998. Phylogenetic relationships and species limits within Phyllotis (Rodentia: Sigmodontinae): concordance between mtDNA sequence and morphology. Journal of Mammalogy. 79:575593.

Steppan, S.J., O. Ramirez, J. Banbury, D. Huchon, V. Pacheco, L. Walker \& A.O .Spotorno. 2006. A molecular reappraisal of the systematics of the leaf-eared mice Phyllotis and their relatives. Pp. 799-826. In: D.A. Kelt, E. Lessa, J. Salazar-Bravo y J.L. Patton (Eds.). The Quintessential Naturalist: Honoring the Life and Legacy of Oliver P. Pearson. University of California Publications in Zoology, Davis.

Teta, P. \& P.E. Ortiz. 2002. Micromamíferos andinos holocénicos del sitio arqueológico Inca Cueva 5, Jujuy, Argentina: tafonomía, zoogeografía y reconstrucción paleoambiental. Estudios Geológicos. 58:117-135.

Teta, P., U.F.J. Pardiñas \& G. D’Elía. 2006. “Abrotrichinos”. Pp. 192-197. In: R.M. Barquez, M.M. Díaz y R. Ojeda (Eds). Mamíferos de Argentina: sistemática y distribución. Sociedad Argentina para el Estudio de los Mamíferos (SAREM), Mendoza.

Thomas, O. 1897. On some small mammals from Salta, N. Argentina. Annals and Magazine of Natural History. (6) 20:214-218.

1913. On small mammals collected in Jujuy by Señor E.Budin. Annals and Magazine of Natural History. (8) 11:136-143.

1918. On small Mammals from Salta and Jujuy collected by Mr. E. Budin. Annals and Magazine of Natural History. (9) 1:186-193.

. 1919. On small mammals from Catamarca "Otro Cerro" North-estern Rioja, collected by Sr.

E. Budin. Annals and Magazine of Natural History. (9) 3:489-500.

. 1920. New species of Reithrodon, Abrocoma, and Scapteromys from Argentina. Annals and Magazine of Natural History. (9) 5:473-478.

1921a. New Rhipidomys, Akodon, Ctenomys and Marmosa from the Sierra Santa Barbara, S.E. Jujuy. Annals and Magazine of Natural History. (9) 7:181-187.

. 1921b. On a further collection of mammals from Jujuy obtained by Sr. E. Budin. Annals and 
Magazine of Natural History. (9) 8:608-617.

1926. Two new mammals from north Argentina. Annals and Magazine of Natural History. (9) 17:311-313

Vervoorst, F. 1982. Noroeste. Conservación de la vegetación natural de la República Argentina. Serie Conservación de la Naturaleza. Simposio XVIII Jornadas Argentinas de Botánica. 2:9-24.

Vitullo, A.D., M.S. Merani, O.A. Reig, A.E. Kajon, O. Scaglia, M.B. Espinosa \& A. Perez-Zapata. 1986. Cytogenetics of South American akodont rodents (Cricetidae): New karyotypes and chromosomal banding patterns of Argentinian and Uruguayan forms. Journal of Mammalogy. 67:69-80.

Yepes, J. 1933. Nuevos roedores para la fauna Argentina. Revista Chilena de Historia Natural. 37:4649.

1935. Consideraciones sobre el género "Andinomys" (Cricetinae) y descripción de una forma nueva. Anales del Museo Argentino de Ciencias Naturales "Bernardino Rivadavia". 38:333-348. 


\section{Apéndice 1}

Lista de localidades puntuales para sigmodontinos de pastizales de neblina del noroeste argentino. Las localidades están ordenadas alfabéticamente. Se indica, entre paréntesis, el Departamento y la Provincia a la que pertenecen y, posteriormente, las coordenadas geográficas. Al final de cada localidad y entre paréntesis se indica el número correspondiente al mapa de la Fig. 1. Las localidades que representan un mismo punto, pero están escritas originalmente de manera distinta, llevan el mismo número y se listan indentadas a continuación.

1 km ENE de Rodeo Pampa, km 59 de Ruta Provincial No 7, 3080 m (Santa Victoria, Salta) 22 ${ }^{\circ}$ 14' 47.7" S; 65'3' 4.3"'W. (4).

6 km SW Hwy 9 on Hwy 18, 1524 m (Ambato, Catamarca) 27 52' S; 65 48' W. (24).

$12 \mathrm{~km}$ W of Quebradita, Tafí del Valle, km 81 along Hwy 307. (Tafí del Valle, Tucumán) 26 45'19” S; 65 44' 39'” W. (36).

- Above Tafí, $2900 \mathrm{~m}$

-- Carapunco, km 81 de la Ruta Provincial N³07, $2960 \mathrm{~m}$.

Abra de Ciénaga Negra, aprox. 3 km al SE, 3090 m (Orán, Salta) 23 19' 49” S; 64 53' 32” W. (15). Agua del Gauchi, aprox. $1 \mathrm{~km}$ al E del Mogote Los Cocos, $2024 \mathrm{~m}$ (Capayán, Catamarca) 28 46' 52" S; 66 $18^{\circ}$ '43' W. (26).

Andalgalá, confluencia de los ríos Minas y Candado, 2600 m (Andalgalá, Catamarca) $27^{\circ} 22^{\prime}$ 59.9'” S; 66 $15^{\prime} 00^{\prime \prime}$ W. (70).

Aprox. $2 \mathrm{~km}$ al SE de Huaico Hondo, sobre Ruta Provincial No 42, al E del Portezuelo, $1992 \mathrm{~m}$ (Valle Viejo, Catamarca) $28^{\circ} 25^{\prime} 10.9^{\prime \prime} \mathrm{S}$; $65^{\circ} 32^{\prime} 40.5^{\prime \prime} \mathrm{W}$. (16).

Aprox. $5 \mathrm{~km}$ (por ruta) al S de Los Toldos, sobre el camino a Vallecito, $1705 \mathrm{~m}$ (Santa Victoria, Salta) $22^{\circ} 19^{\prime} 06^{\prime \prime} \mathrm{S} ; 64^{\circ} 43^{\prime} 08^{\prime \prime}$ W. (71)

Aprox.7 km al NO de la finca de la familia Usandivara, Altos de Medina, $1717 \mathrm{~m}$. (Burruyacú, Tucumán) $22^{\circ} 23.229^{\prime}$ S; 65 $05.358^{\prime}$ W. (17).

Aprox. $10 \mathrm{~km}$ al W de Los Varela, sobre Ruta Provincial No 4, Sierra de Humaya, 2006 m. (Ambato, Catamarca) $27^{\circ} 56^{\prime} 12.1$ ' S; $65^{\circ} 56^{\prime} 52.8^{\prime \prime}$ W. (32).

Aprox. $10 \mathrm{~km}$ al S de Hualinchay, sobre el camino a Lara, $2316 \mathrm{~m}$ (Trancas, Tucumán) 26 19' 20.2" S; 65 $36^{\prime} 45.5^{\prime \prime}$ W. (2).

.- $10 \mathrm{~km}$ by road south of Hualinchay on the trail to Lara.

Aprox. $15 \mathrm{~km}$ al W de Escoipe, sobre Ruta Provincial No 33, $2680 \mathrm{~m}$ (Chicoana, Salta) $25^{\circ} 10^{\prime} \mathrm{S} ; 65^{\circ}$ 49' W. (5).

.- Aprox. $15 \mathrm{~km}$ al W de Escoipe, sobre Ruta Provincial No 33.

Aprox. 16 km de Hualinchay, sobre el camino a Lara, 2750 m (Trancas, Tucumán) $26^{\circ} 19.532$ ' S; $65^{\circ}$ 38.853' W. (35).

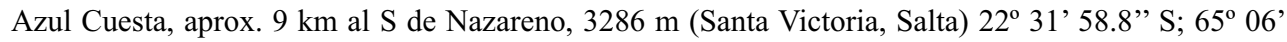
$59.2 " \mathrm{~W} .(6)$.

Bárcena, 9 km NW, 2655 m. (Tumbaya, Jujuy) $23^{\circ} 57^{\prime} \mathrm{S} ; 65^{\circ} 30^{\prime}$ W. (23).

-- 9 km NW Bárcena

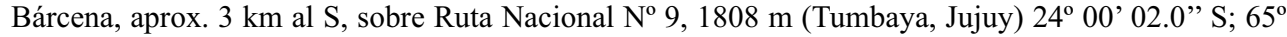
26' 51.6"'W. (18).

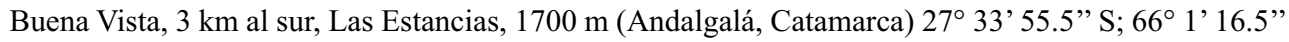
W. (69). 
Campo Quijano, aprox. $5 \mathrm{~km}$ al NO, km 30 de la Ruta Nacional № 51 (Quebrada del Toro), altura

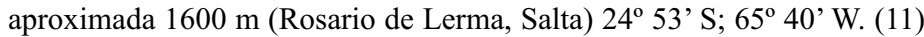

Cerro Hermoso (Ledesma, Jujuy) 23 34' S; 64 51' W. (10) -- Cerro Hermoso (cercanías), $2800 \mathrm{~m}$.

Cerro Muñoz, arriba del Puesto de Ibáñez, subiendo por Santa Cruz, 3300 m (Tafí del Valle, Tucumán) $26^{\circ} 53$ ' 36.05' S; 65 48' 32.55' W. (63)

Cerro Muñoz, Puesto de Ibáñez, subiendo por Santa Cruz, 2650 m (Tafí del Valle, Tucumán) $26^{\circ} 53^{\text {' }}$ 10.22 " S; $65^{\circ} 47$ ' $8.45^{\prime \prime} \mathrm{W}$. (65)

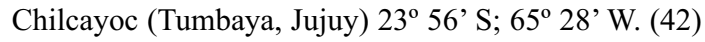

Chilcayoc, puente Bailey, aprox. $4.6 \mathrm{~km}$ al NO de la intersección de la Ruta Nacional No 9 y el camino hacia el puente Bailey, 2239 m (Tumbaya, Jujuy) $23^{\circ} 57^{\prime} \mathrm{S} ; 65^{\circ} 30^{\prime} \mathrm{W}$. (51)

Ciénaga (Tafí del Valle, Tucumán) $26^{\circ} 46^{\prime} \mathrm{S} ; 65^{\circ} 39^{\prime}$ W. (55) .- La Ciénaga (=Ciénaga?), $8200 \mathrm{ft}$.

Cuesta del Obispo, aprox. $5 \mathrm{~km}$ al NE de Piedra del Molino, sobre Ruta Provincial No $33,3174 \mathrm{~m}$. (Chicoana, Salta) $25^{\circ} 10$ ' 36" S; 65 51' 4" W. (34)

Cumbre del Taficillo, al NE de las Agüitas, Parque Biológico Sierra de San Javier (Tafí Viejo, Tucumán) $26^{\circ} 41^{\prime} 51.7^{\prime \prime} \mathrm{S} ; 65^{\circ} 20^{\prime} 20.4$ "W. (37)

El Corralito, aprox. $23 \mathrm{Km}$ al SO de Campo Quijano, sobre ruta Nac. № 51 (Rosario de Lerma, Salta) $24^{\circ} 58^{\prime} \mathrm{S} ; 65^{\circ} 48^{\prime}$ W. (27)

El Duraznillo, Cerro Calilegua, 2600 m. (Valle Grande, Jujuy) $23^{\circ} 35^{\prime}$ S; 64 55' W. (7).

.- Alto Calilegua, El Duraznillo, $3000 \mathrm{~m}$

.- Cerro Calilegua, El Duraznillo, $2600 \mathrm{~m}$.

.- Duraznillar, $2500 \mathrm{~m}$.

El Espinillo, Campo del Pucará, Las Estancias, extremo sur de la Sierra del Aconquija, $1950 \mathrm{~m}$ (Andalgalá, Catamarca) $27^{\circ} 35^{\prime} 25.5^{\prime}$ ' S; 66 8'34.5” W. (67)

El Infiernillo, $7 \mathrm{~km}$ al NW, por huella electroducto a La Alumbrera, $3400 \mathrm{~m}$ (Tafí del Valle, Tucumán) $26^{\circ} 43^{\prime} \mathrm{S} ; 65^{\circ} 50^{\prime}$ W. (62)

El Infiernillo, 3000 m. (Tafí del Valle, Tucumán) $26^{\circ} 44^{\prime} 37.5$ ” S; $65^{\circ} 45^{\prime} 19.5$ ” W. (28)

.- Above Tafí del Valle, $9500 \mathrm{ft}$.

-- Camino a Amaicha, km 83.

- El Infiernillo.

.- El Infiernillo, $19 \mathrm{~km} \mathrm{NW}$ Tafí del Valle, $3000 \mathrm{~m}$.

.- El Infiernillo Dept., NW of Tafí del Valle.

.- El Infiernillo, km 83 along hwy 307, 10000 feet.

-- Infiernillo.

.- Infiernillo, $3000 \mathrm{~m}$.

-- Paso El Infiernillo.

-- Tafí del Valle, $9500 \mathrm{ft}$.

-- Tafí del Valle, km 83, $2900 \mathrm{~m}$.

El Rincón, 1 km al N, 2450 m (Tafí del Valle, Tucumán) $26^{\circ} 57^{\prime}$ S; $65^{\circ}$ 45’ W. (64)

El Rincón, vertiente oeste de la Loma Pelada, Valle de Tafí, 2300 m (Tafí del Valle, Tucumán) $26^{\circ} 56^{\prime}$ 22.5 " S; 65० 46' 22.5 " W. (68)

El Rodeo, $0.75 \mathrm{~km} \mathrm{~S}$ village limits along Hwy 4, $1372 \mathrm{~m}$. (Ambato, Catamarca) $28^{\circ} 13^{\prime} 7.5^{\prime \prime} \mathrm{S} ; 65^{\circ}$ 52 ' 34.5 ' W. (49)

El Rodeo, 1.5 km NE Hwy 4, 1371 m (Ambato, Catamarca) 28 10’ 48” S; 65 52' 12” W. (25) .-El Rodeo, $1.5 \mathrm{~km} \mathrm{NE}$ of Hwy 4, el: $4500 \mathrm{ft}$ 
Estancia Narvaez, 5,5 Km N Las Chacritas en Ruta Provincial No 1, 1782 m. (Ambato, Catamarca) $27^{\circ}$ $39^{\prime} \mathrm{S} ; 65^{\circ} 56^{\prime}$ W. (52)

Hualinchay, 1,9 km NE, en Ruta Provincial No 311, 1732 m (Trancas, Tucumán) 28 18' S; 65 35’ W. (53)

Hualinchay, 2,2 Km NE, en Ruta Provincial No 311, 1732 m. (Trancas, Tucumán) 28 18' S; 65 35' W. (54)

Hualinchay, sobre el camino a Cafayate, $1861 \mathrm{~m}$ (Trancas, Tucumán) 26ำ $18^{\prime} \mathrm{S} ; 65^{\circ} 36^{\prime}$ W. (12)

$\mathrm{Km} 33$ de la Ruta Provincial No 47, al S de Capillitas, 2500 m (Andalgalá, Catamarca) $27^{\circ} 25^{\prime} \mathrm{S} ; 66^{\circ}$ 25 ' W. (13)

La Angostura (Tafí del Valle, Tucumán) $26^{\circ} 56^{\prime} 25.5^{\prime}$ S; $65^{\circ} 42 ’ 10.5$ ” W. (31)

--La Angostura, barranca de los roedores

La Angostura, 1 km al N, 2122 m (Tafí del Valle, Tucumán) $26^{\circ} 55^{\prime}$ S; 65³9' W. (61)

La Antena, Sierra del Centinela, al S de El Fuerte, 2350 m. (Santa Bárbara, Jujuy) $24^{\circ} 17.941^{\prime}$ S; $64^{\circ}$ 23.155' W. (40)

La Cruz, Cumbre del Taficillo, Parque Biológico Sierra de San Javier, 1907 m. (Tafí Viejo, Tucumán) $26^{\circ} 41$ ' 11.7" S; 65 19' 56.4" W. (29)

-- Cerro San Javier, $2000 \mathrm{~m}$.

-- Cerro San Javier, $2300 \mathrm{~m}$.

-- Horco Molle, Taficillo.

-- Sierra de Tafí Viejo, Tucumán, $2000 \mathrm{~m}$.

.- Tafí Viejo, $2300 \mathrm{~m}$.

.- Taficillo

La Herradura, $12 \mathrm{~km}$ al SO de El Fuerte, sobre Ruta Provincial No 6, 1428 m (Santa Bárbara, Jujuy) $24^{\circ} 18^{\prime}$ 05.7' S; 64 29' 38.7'” W. (19)

Las Agüitas, cumbres del Taficillo, 1700 m. (Tafí Viejo, Tucumán) $26^{\circ} 42^{\prime}$ S; 65²1’ W. (3)

.- Cumbre del Taficillo, Las Agüitas, Parque Biológico Sierra de San Javier

-- La Agüadita.

.- Las Agüitas, cumbre del Taficillo.

Las Chacritas, aprox. $28 \mathrm{~km}$ al NNW de Singuil, sobre Ruta Provincial No $1,1888 \mathrm{~m}$ (Ambato, Catamarca) $27^{\circ} 42^{\prime} 24.2^{\prime}$ ' S; $65^{\circ} 54^{\prime} 40.6^{\prime \prime}$ W. (1)

León, $1.6 \mathrm{~km}$ al O, $1770 \mathrm{~m}$. (Doctor Manuel Belgrano, Jujuy) 24 02’ 7.5” S; 65²6’ 52.5” W. (50). .- $1 \mathrm{mi}$ W León, $5800 \mathrm{ft}$

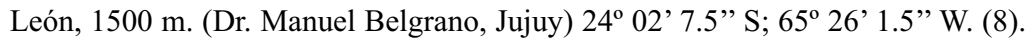

- Arroyo La Tablada

.- Arroyo La Tablada, León.

-- León.

.- León, Arroyo La Tablada.

-- San León de Jujuy.

Loma Atravesada, aprox. $3 \mathrm{~km}$ al NO del Puesto de Leandro Vega, NO de Chumbicha, $1369 \mathrm{~m}$. (Capayán, Catamarca) $28^{\circ} 47^{\prime} \mathrm{S}$; 66 $66^{\circ}$ ' W. (33)

Minas Capillitas, 3200 m (Andalgalá, Catamarca) 27²0’31.5” S; 66²3’25.5” W. (57)

Mogote Las Trampas, aprox. $15 \mathrm{~km}$ al NW de Chumbicha, $2300 \mathrm{~m}$ (Capayán, Catamarca) $28^{\circ} 44^{\prime}$ $30.66^{\prime \prime} \mathrm{S} ; 66^{\circ} 19^{\prime} 14.05^{\prime \prime}$ W. (48)

Ñorco, $8200 \mathrm{ft}$ (Trancas, Tucumán) $26^{\circ} 30^{\prime} 46.5^{\prime}$ S; 65³3'10.5” W. (56)

.- Norco Vipos, $2500 \mathrm{~m}$

Ñorco, Vipos, 1500 - 2000 m (Trancas, Tucumán) 26³0’ 43.5” S; 65³2' 58.5” W. (59).

.- Ñorco (= Norco Simbolán), Tucumán at 1500-2000 m. 
Otro Cerro, 45 kilometers west of Chumbicha, about 3000 m (Capayán, Catamarca) 28 45' S, 66 $17^{\circ}$ ' W. (14).

.- $45 \mathrm{~km}$ west of Chumbicha, about $3000 \mathrm{~m}$.

-- Otro Cerro.

-- Otro Cerro, $2500 \mathrm{~m}$.

- Otro Cerro, $3000 \mathrm{~m}$.

-- Otro Cerro, $3018 \mathrm{~m}$

-- Otro Cerro, $9900 \mathrm{ft}$.

.- Otro Cerro, about $18 \mathrm{~km} \mathrm{NNW}$ of Chumbicha, $3000 \mathrm{~m}$.

-- Otro Cerro, southermost Sierra de Ambato.

Pampa Verde, aprox. $8 \mathrm{~km}$ al OSO de Los Toldos y al S del Cerro Bravo, $2400 \mathrm{~m}$ (Santa Victoria, Salta) $22^{\circ} 17^{\prime} \mathrm{S} ; 64^{\circ} 48^{\prime}$ W. (9)

Río Vallecito, 2900 m (Andalgalá, Catamarca) $27^{\circ} 17^{\prime} 34.5$ ' S; 66 04’ 1.5” W. (58)

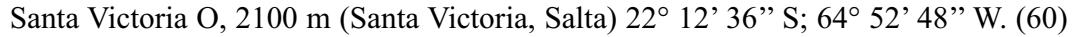

.- Santa Victoria O, $2200 \mathrm{~m}$.

Sobre ruta 307, km 72 (Tafí del Valle, Tucumán) $26^{\circ} 48^{\prime} 52.5^{\prime}$ S; $65^{\circ} 43^{\prime} 25.5^{\prime}$ W. (38) - ruta $307, \mathrm{~km} 72$.

SW de Hualinchay, 2822 m (Trancas, Tucumán) 26² 20’ S; 65³9’ W. (44)

Tafí del Valle (Tafí del Valle, Tucumán) $26^{\circ} 50^{\prime} 37.5$ ” S; 65² 42’34.5” W. (39)

-- Tafí del Valle, $2100 \mathrm{~m}$.

-- Tafí del Valle, $7000 \mathrm{ft}$.

Tafí del Valle, 2800 m. (Tafí del Valle, Tucumán) 26 46’37.5” S; 65 43’ 43.5” W. (43)

.- Tafí del Valle, km 78, $2700 \mathrm{~m}$.

Termas de Reyes, aprox. $15 \mathrm{~km}$ al N, sobre Ruta Provincial No 4 (Doctor Manuel Belgrano, Jujuy) $24^{\circ}$ 7' 4.5" S; 65'29' 19.5" W. (20)

Termas de Reyes, mirador, sobre Ruta Provincial No 4 (Doctor Manuel Belgrano, Jujuy) 24 9' 46.5", $\mathrm{S} ; 65^{\circ} 29^{\prime} 58.5^{\prime \prime}$ W. (21)

Unión entre las rutas provinciales $\mathrm{N}^{\circ} 9$ y 18, $3.4 \mathrm{~km}$ al S, sobre Ruta Provincial No 18, 1529 m (Paclín, Catamarca) $27^{\circ} 49^{\prime} \mathrm{S} ; 65^{\circ} 47^{\prime}$ W. (22)

Valle Encantado, Parque Nacional Los Cardones, 3000 m. (Chicoana, Salta) 25 11' 48.48' S; 65 50' 33.93" W. (46)

-- Valle Encantado, $3500 \mathrm{~m}$.

-- Valle Encantado, C. del Obispo.

-- Valle Encantado, Los Cardones National Park, $3000 \mathrm{~m}$

Villa Nougués (Lules, Tucumán) 2650'55.5” S; 65²3’19.5” W. (47)

Villa Nougués, aprox. $2 \mathrm{~km}$ al N, sobre Ruta Provincial No 338 , a la altura de la antena repetidora del Canal 10 de televisión. (Lules, Tucumán) $26^{\circ} 52^{\prime} \mathrm{S} ; 6^{\circ} 23^{\prime}$ W. (30)

Zanja del Chivo, La Angostura, $1850 \mathrm{~m}$ (Tafí del Valle, Tucumán) $26^{\circ} 56^{\prime} 46.5^{\prime}$ S; $65^{\circ} 40^{\prime} 4.5^{\prime \prime}$ W. (41)

Zanjón de Tafí, 2 km al sudoeste de Tafí del Valle, 2000 m (Tafí del Valle, Tucumán) 26 51' 43” S; $65^{\circ} 43^{\prime}$ 6"'W. (66) 


\title{
Apéndice 2
}

Lista de localidades no específicas para sigmodontinos de pastizales de neblina del noroeste argentino. Las localidades se ordenan alfabéticamente.

\author{
Above Tafí (Tucumán) \\ Aconquija, $3000 \mathrm{~m}$ \\ Cerro San Javier (Tucumán) \\ Cumbre de Mala Mala, Sierra de Aconquija, 3300 m (Tucumán) \\ Las Paras, about 4000 m (Chicligasta, Tucumán) (= Las Pavas). \\ Las Paras, 3018 m (Chicligasta, Tucumán) (= Las Pavas). \\ Las Paras, $9900 \mathrm{ft}$ (Chicligasta, Tucumán) (= Las Pavas). \\ Mountains W of Yala (Jujuy) \\ Nr. Tucumán, Mala Mala (Tucumán) \\ Sierra de Aconquija (Tucumán) \\ Tafí Viejo, cerros occidentales (Tucumán) \\ Tafí del Valle, above (Tucumán) \\ W of Yala (Jujuy) \\ Yala mountain west of, $10000 \mathrm{ft}$ (Jujuy)
}

Apéndice 3

Lista de los especímenes examinados y registros adicionales de sigmodontinos de pastizales de neblina.

\section{Especies de presencia confirmada en pastizales de neblina}

\begin{abstract}
Akodon boliviensis
Especimenes examinados. SALTA: $1 \mathrm{~km}$ ENE de Rodeo Pampa, km 59 de Ruta Provincial $\mathrm{N}^{\mathrm{o}} 7$, 3080 m (JPJ 1330, 1334); Abra de Ciénaga Negra, aprox. 3 km al SE, 3090 m (JPJ 719, 720, 724, 725, 728, 734, 735, 737, 739); Azul Cuesta, aprox. 9 km al S de Nazareno, 3286 m (JPJ 673); Pampa Verde, aprox. $8 \mathrm{~km}$ al OSO de Los Toldos y al S del Cerro Bravo, $2400 \mathrm{~m}$ (JPJ 335).

Registros adicionales. Ninguno.
\end{abstract}

\section{Akodon lutescens}

Especimenes examinados. CATAMARCA: aprox. $2 \mathrm{~km}$ al SE de Huaico Hondo, sobre Ruta Provincial No 42, al E del Portezuelo, 1992 m (JPJ .398, 400, 408, 414, 417, 428, 429); Las Chacritas, aprox. 28 km al NNW de Singuil, sobre Ruta Provincial No 1, 1888 m (JPJ 515, 517, 523, 533, 535, 542); unión entre las rutas provinciales $\mathrm{N}^{\circ} 9$ y 18, $3.4 \mathrm{~km}$ al S, sobre Ruta Provincial No 18,1529 m (JPJ 3-5, 7, 8, 12, 14, 16-18, 20, 21, 23, 30, 32, 33, 36, 37, 39, 43, 1113-1116, 1119, 1120, 1123, 1133, 1134, 1143-1145, 1148, 1150). JUJUY: Bárcena, aprox. 3 km al S, sobre Ruta Nacional No 9, 1808 m (JPJ 128, 129, 623, 625, 627-629, 631, 634, 635, 641, 642, 648, 649, 654, 656, 658, 659, 666); Cerro Hermoso (MACN 19474); El Duraznillo, Cerro Calilegua, 2600 m (CML 1734); La Herradura, 12 km al SW de El Fuerte, sobre Ruta Provincial No 6, 1428 m (JPJ 573, 574, 579, 581, 587, 588, 601, 603, 609, 612); León, Arroyo La Tablada (MMPMa 1241, 1243, 1254); Termas de Reyes, aprox. $15 \mathrm{~km}$ al N, sobre Ruta Provincial No 4 (JPJ 293, 309-314, 316-318, 328, 331, 332); Termas de Reyes, mirador, sobre Ruta Provincial No 4 (JPJ 125-127, 299, 301, 305, 306, 307, 320, 323, 325-327). SALTA: $1 \mathrm{~km}$ ENE de Rodeo Pampa, km 59 de Ruta Provincial No 7, 3080 m (JPJ 1320-1322); Pampa Verde, aprox. 8 km al OSO de Los Toldos y al S del Cerro Bravo, 2400 m (JPJ 337, 339, 341, 342, 345, 346, 348-350, 352, 355-357, 359, 360, 362-364, 366). TUCUMAN: Aconquija, 3000 m (MACN 34-1127); aprox. $7 \mathrm{~km}$ al 
NO de la finca de la familia Usandivara, Altos de Medina, 1717 m (JPJ 816, 832, 836, 849); aprox. 10 $\mathrm{km}$ al S de Hualinchay, sobre el camino a Lara, $2300 \mathrm{~m}$ (JPJ 492); Hualinchay, sobre el camino a Cafayate, 1861 (JPJ 172, 179-181, 184, 185, 192, 196, 197, 205-207, 210, 221, 222).

Registros adicionales. CATAMARCA: 6 km SW Hwy 9 on Hwy 18, 1524 m; El Rodeo, 1.5 km NE Hwy 4, 1371 m (Mares et al. 1997 como Akodon caenosus). JUJUY: 9 km NW Bárcena; Cerro Calilegua, El Duraznillo, 2600 m (Díaz 1999; Díaz \& Barquez, 2007 como A. lutescens); León (Vitullo et al. 1986 como A. puer); León, 1500 m (Thomas 1918 como A. puer caenosus). TUCUMAN: Las Agüitas, cumbres del Taficillo, $1700 \mathrm{~m}$ (Capllonch et al. 1997 como A. caenosus).

\section{Akodon simulator}

Especimenes examinados. CATAMARCA: Agua del Gauchi, aprox. $1 \mathrm{~km}$ al E del Mogote Los Cocos, 2024 m (JPJ 1254, 1277, 1278, 1303); El Espinillo, Campo del Pucará, Las Estancias, extremo sur de la Sierra del Aconquija, 1950 m (PEO-e 121); Mogote Las Trampas, aprox. $15 \mathrm{~km}$ al NW de Chumbicha, $2300 \mathrm{~m}$ (JPJ 1418); unión entre las rutas provinciales $\mathrm{N}^{\circ} 9$ y 18, $3.4 \mathrm{~km}$ al S, sobre Ruta Provincial No 18, 1529 m (JPJ 22, 27, 40, 1128, 1131, 1152, 1153). JUJUY: La Herradura, $12 \mathrm{~km}$ al SW de El Fuerte, sobre Ruta Provincial No 6, 1428 m (JPJ 582, 608). SALTA: Campo Quijano aprox. 5 km al NO, km 30 de la ruta Nacional 51 (Quebrada del Toro), alt. aproximada 1600 m (JPJ 109, 138); El Corralito, aprox. $23 \mathrm{~km}$ al SO de Campo Quijano, sobre ruta Nac. No 51 (JPJ 145, 146, 147, 148). TUCUMAN: aprox. $10 \mathrm{~km}$ al S de Hualinchay, sobre el camino a Lara, $2300 \mathrm{~m}$ (JPJ 437, 496); Cerro San Javier, 2300 m (MACN 26.134-26.138); Hualinchay, sobre el camino a Cafayate, $1861 \mathrm{~m}$ (JPJ 155, 174, 182, 186, 188, 199, 201, 202, 204, 213, 214, 216, 224, 225, 231, 234, 246); Villa Nougués, aprox. $2 \mathrm{~km}$ al N, sobre Ruta Provincial No 338, a la altura de la antena repetidora del Canal 10 de televisión (JPJ 262, 265, 266, 280, 288).

Registros adicionales. CATAMARCA: 6 km SW Hwy 9 on Hwy 18, 1524 m; Otro Cerro (Mares et al. 1997); Otro Cerro, 2500 m (Myers 1989); El Rodeo, 1.5 km NE Hwy 4, 1372 m (Mares et al. 1997). TUCUMAN: above Tafí (Myers 1989); Infiernillo (Bianchi et al. 1971 como A. varius simulator); Tafí Viejo, $2300 \mathrm{~m}$ (Capllonch et al. 1997).

\section{Akodon spegazzinii}

Especimenes examinados. CATAMARCA: Agua del Gauchi, aprox. $1 \mathrm{~km}$ al E del Mogote Los Cocos, 2024 m (JPJ 1233-1240, 1245, 1246, 1248, 1249, 1256, 1259, 1261-1268, 1282-1285, 1287, 1290, 1291, 1298-1302); aprox. $10 \mathrm{~km}$ al W de Los Varela, sobre Ruta Provincial No 4, Sierra de Humaya, 2006 m (JPJ 1308, 1309); aprox. 2 km al SE de Huaico Hondo, sobre Ruta Provincial No 42, al E del Portezuelo, 1992 m (JPJ 399, 401-403, 405-407, 409-411, 415, 416, 418, 422, 426, 427, 780, 783-789, 791-800, 803, 804, 806); Buena Vista, 3 km al sur, Las Estancias, 1700 m (PEO-e 190); El Espinillo, Campo del Pucará, Las Estancias, extremo sur de la Sierra del Aconquija, $1950 \mathrm{~m}$ (PEO-e 122); km 33 de la Ruta Provincial No 47, al S de Capillitas (JPJ 675, 678, 682-684, 687, 689-691, 697701, 708, 710-712, 714, 716, 717); Las Chacritas, aprox. $28 \mathrm{~km}$ al NNW de Singuil, sobre Ruta Provincial No 1, $1888 \mathrm{~m}$ (JPJ 512-514, 516, 518, 519, 521, 522, 524, 528, 529, 531, 534, 537-540, 543$548,550,554-559,561,562,570,571)$; Loma Atravesada, aprox. $3 \mathrm{~km}$ al NO del puesto de Leandro Vega, NO de Chumbicha, 1369 m (JPJ 1158, 1160, 1161, 1163-1166, 1171); Mogote Las Trampas, aprox. $15 \mathrm{~km}$ al NW de Chumbicha, $2300 \mathrm{~m}$ (JPJ 1443); Otro Cerro, 45 kilometres west of Chumbicha, about $3000 \mathrm{~m}$ (BMNH 19.2.7.44 Holotipo A. alterus [material fotográfico]); unión entre las rutas provinciales $N^{\circ} 9$ y 18, 3,4 km al S, sobre Ruta Provincial No 18, 1529 m (JPJ 1121, 1125, 1135, 1141, 1155). SALTA: aprox. $15 \mathrm{~km}$ al W de Escoipe, sobre Ruta Provincial No 33, $2680 \mathrm{~m}$ (JPJ 50, 52-56, 58, 59, 66, 69, 70, 76, 77, 80, 82, 83, 85, 88, 1033, 1035-1042, 1044, 1046, 1047, 1049-1051, 1053, 1054, 1058); Campo Quijano, aprox. $5 \mathrm{~km}$ al NO, km 30 de la ruta Nacional 51 (Quebrada del Toro), alt. aprox. $1600 \mathrm{~m}$ (JPJ 139, 150); Cuesta del Obispo, aprox. $5 \mathrm{~km}$ al NE de Piedra del Molino, sobre Ruta Provincial No 33, 3174 m (JPJ 1211, 1212); El Corralito, aprox. 23 km al SO de Campo Quijano, sobre 
ruta Nac. N 51 (JPJ 143); Valle Encantado, Parque Nacional Los Cardones, 3000 m (PEO-e 111). TUCUMAN: $12 \mathrm{~km}$ W of Quebradita, Tafí del Valle, km 81 along Hwy 307 (CML 3455-3459); Aconquija, 3000 m (MACN 29.285, 29.305, 29.306, 29.308, 29.310, 29.316, 29.335-29.339, 29.350, 29.369-29.371, 29.378, 34.845, 34.851, 34.859, 34.860, 34.884, 34.908, 34.910, 34.911, 34.915, $34.916,34.922$, 34.966, 34.1070, 34.1105, 34.1122, 34.1125, 34.1130); aprox. $7 \mathrm{~km}$ al NO de la finca de la familia Usandivara, Altos de Medina, 1717 m (JPJ 808, 809, 811-815, 817, 819-830, 833-835, 838, 840, 842-848, 850, 854, 855); aprox. $10 \mathrm{~km}$ al S de Hualinchay, sobre el camino a Lara, $2316 \mathrm{~m}$ (JPJ, 430-434, 436, 438, 439, 448, 452, 454, 455, 457, 458, 462-464, 466, 477, 479, 480, 484-486, 489-491, 494, 497, 499, 500, 508, 754-759, 773, 971-976, 978, 980, 983-985, 988-991, 995, 996, 999, 1001-1004, 1006-1008, 1217-12191223); aprox. 16 km de Hualinchay, sobre el camino a Lara, 2750 m (JPJ 741745, 747, 750, 764, 766, 775, 778, 779); Camino a Amaicha, km 83 (CML 698, 701, 710); Carapunco, km 81 de la Ruta Provincial №307, 2960 m (JPJ 1065-1069, 1072-1074, 1076, 1077, 1079-1082, 10841098); Cerro Muñoz, arriba del Puesto de Ibáñez, subiendo por Santa Cruz, 3300 m (PEO 36); Cerro San Javier, 2300 m (MACN 26.139); Cumbre del Taficillo, al NE de Las Agüitas, Parque Biológico Sierra de San Javier (JPJ 111, 113, 115, 117, 119, 121); Cumbre del Taficillo, Las Agüitas, Parque Biológico Sierra de San Javier (CML 4038, 4041); El Infiernillo, $7 \mathrm{~km}$ al NW, por huella electroducto a La Alumbrera, 3400 m (PEO 4); El Infiernillo, 3000 m (CML 691); El Infiernillo, km 83 along hwy 307, 10000 feet (CML 3468-3472); El Rincón, vertiente oeste de la Loma Pelada, Valle de Tafí, 2300 m (PEO-e 161); Hualinchay, sobre el camino a Cafayate, 1861 (JPJ 157, 160, 162, 164, 165, 171, 177 , 193, 211, 226, 233, 237, 238, 241, 248, 250, 251, 252); Infiernillo, 3000 m (CML 692); La Agüadita (CML 4941-4944); La Angostura, 1 km al N, 2122 m (PEO 1); La Angostura, barranca de los roedores (PEO-e 26); La Cruz, Cumbre del Taficillo, Parque Biológico Sierra de San Javier, 1907 m (JPJ 856869, 871-893, 895-910, 912-919); Las Agüitas, cumbre del Taficillo (CML 4018, 4022, 4023, 4025, 4027-4029, 4031, 4033-4035, 4037, 4040, 4042); Sobre ruta 307, km 72 (MMPMa 2386, 2388); Tafí del Valle (CML 2058, 2061); Tafí del Valle, km 83, 2900 m (CML 1837); Villa Nougués, aprox. 2 km al N, sobre Ruta Provincial No 338, a la altura de la antena repetidora del Canal 10 de televisión (JPJ 257, 261, 263, 264, 267-273, 281, 283-287, 289); Zanjón de Tafí, 2 km al sudoeste de Tafí del Valle (PEO-e 179).

Registros adicionales. CATAMARCA: Otro Cerro, 45 kilometres west of Chumbicha, about 3000 m (Thomas 1919 como Akodon alterus); Otro Cerro, 3000 m (Díaz 1999 como A. alterus). TUCUMAN: above Tafí, $2900 \mathrm{~m}$; El Infiernillo, $19 \mathrm{~km}$ NW Tafí del Valle, $3000 \mathrm{~m}$ (Myers et al. 1990 como A. s. spegazzinii); La Angostura (Ortiz \& Pardiñas 2001); Las Agüitas, cumbres del Taficillo, $1700 \mathrm{~m}$ (Capllonch et al. 1997 como A. tucumanensis); Tafí del Valle, $2100 \mathrm{~m}$ (Myers et al. 1990 como A. s. spegazzinii); Villa Nougués (Bianchi et al. 1971 como A. boliviensis tucumanensis).

\section{Akodon sylvanus}

Especimenes examinados. JUJUY: La Antena, Sierra del Centinela, al S de El Fuerte, $2350 \mathrm{~m}, 28$ (JPJ 925-968); La Herradura, 12 km al SW de El Fuerte, sobre Ruta Provincial No 6, 1428 m, 20 (JPJ 576-615).

Registros adicionales. Ninguno.

\section{Necromys lactens}

Especimenes examinados. CATAMARCA: aprox. $2 \mathrm{~km}$ al SE de Huaico Hondo, sobre Ruta Provincial No 42, al E del Portezuelo, 1992 m (JPJ 419, 421); Las Chacritas, aprox. 28 km al NNW de Singuil, sobre Ruta Provincial $\mathrm{N}^{\mathrm{o}} 1,1888 \mathrm{~m}$ (JPJ 552, 560, 566); unión entre las rutas provinciales $\mathrm{N}^{\mathrm{o}}$ 9 y 18, 3.4 km al S, sobre Ruta Provincial No 18, 1529 m (JPJ 6, 38, 44). JUJUY: Bárcena, 9 km NW, $2655 \mathrm{~m}$ (liberado); Bárcena, aprox. $3 \mathrm{~km}$ al S, sobre Ruta Nacional No 9, 1808 m (JPJ 630, 633, 647, 650, 651, 652, 657, 663, 664, 669, 670, 672); Cerro Hermoso (MACN 19.517); El Duraznillo, Cerro Calilegua, 2600 m (CML 1736, 1737); La Antena, Sierra del Centinela, al S de El Fuerte, 2350 m (JPJ 
952-954); León (MMPMa 2158, 2161, 2169, 2185, 2190); Termas de Reyes, aprox. $15 \mathrm{~km}$ al N, sobre Ruta Provincial No 4 (JPJ 123, 124, 290, 308). SALTA: 1 km ENE de Rodeo Pampa, km 59 de Ruta Provincial No 7, 3080 m (JPJ 1315); Abra de Ciénaga Negra, aprox. 3 km al SE, 3090 m (JPJ 721, 729, 731, 736, 740); aprox. $5 \mathrm{~km}$ (por ruta) al S de Los Toldos, sobre el camino a Vallecito, $1705 \mathrm{~m}$ (JPJ 1576); aprox. $15 \mathrm{~km}$ al W de Escoipe, sobre Ruta Provincial No 33, $2680 \mathrm{~m}$ (JPJ 47, 61, 62, 63, 72, 73, 75, 78, 79, 89); El Corralito, aprox. $23 \mathrm{~km}$ al SO de Campo Quijano, sobre ruta Nac. $\mathrm{N}^{\mathrm{o}} 51$ (JPJ 152, 153); Pampa Verde, OSO de Los Toldos y al S del Cerro Bravo, 2400 m (JPJ 361). TUCUMAN: aprox. $10 \mathrm{~km}$ al S de Hualinchay, sobre el camino a Lara, 2316 m (JPJ 447); aprox. 16 km de Hualinchay, sobre el camino a Lara, 2750 m (JPJ 768, 770); El Rincón, vertiente oeste de la Loma Pelada, Valle de Tafí, 2300 m (PEO-e 162); Hualinchay, sobre el camino a Cafayate, $1861 \mathrm{~m}$ (JPJ 154, 195, 203, 235, 236, 253); La Angostura, barranca de los roedores (PEO-e 27); SW de Hualinchay, $2822 \mathrm{~m}$ (liberado); ruta 307, km 72 (MMPMa 2985); Tafí del Valle, 2800 m (CML 2062); Tafí del Valle, km 78, 2700 m (CML 1836); Zanjón de Tafí, 2 km al sudoeste de Tafí del Valle, 2000 m (PEO-e 180).

Registros adicionales. CATAMARCA: $45 \mathrm{~km}$ west of Chumbicha, about $3000 \mathrm{~m}$ (Thomas 1919 como Akodon orbus); Otro Cerro, 3000 m (Mares et al. 1997 como Bolomys lactens). JUJUY: Alto Calilegua, El Duraznillo, 3000 m; (Díaz 1999 como B. lactens; Díaz \& Barquez 2007); Cerro Hermoso (cercanías), 2800 m (Heinonen \& Bosso 1994); Chilcayoc (Díaz 1999 como B. lactens; Díaz \& Barquez 2007); León, 1500 m (Thomas 1918 como A. lactens). SALTA: aprox. $15 \mathrm{~km}$ al W de Escoipe, sobre Ruta Provincial №33 (Díaz et al. 2000 como B. lactens); Valle Encantado, Los Cardones National Park, 3000 m (Ortiz et al. 2000). TUCUMÁN: La Angostura (Ortiz \& Pardiñas 2001, como Necromys cf. $N$. lactens); Las Paras, about $4000 \mathrm{~m}$ (Thomas 1926, como B. negrito).

\section{Necromys lasiurus}

Especimenes examinados. CATAMARCA: Las Chacritas, aprox. $28 \mathrm{~km}$ al NNW de Singuil, sobre Ruta Provincial No 1, 1888 m (JPJ 530).

Registros adicionales. Ninguno.

\section{Oxymycterus paramensis}

Especimenes examinados. JUJUY: Cerro Hermoso (MACN 19519); La Antena, Sierra del Centinela, al S de El Fuerte, 2350 m (JPJ 957, 961, 967); La Herradura, 12 km al SW de El Fuerte, sobre Ruta Provincial No 6, 1428 m (JPJ 575); Termas de Reyes, mirador, sobre Ruta Provincial No 4 (JPJ 295, 302, 303). SALTA: Abra de Ciénaga Negra, aprox. 3 km al SE, 3090 m (JPJ 730, 732, 733); aprox. 5 $\mathrm{km}$ (por ruta) al S de Los Toldos, sobre el camino a Vallecito, 1705 m (JPJ 1620); Pampa Verde, OSO de Los Toldos y al S del Cerro Bravo, 2400 m (CML 7251; JPJ 343, 367). TUCUMÁN: Cerro San Javier, 2300 m (MACN 26.146).

Registros adicionales. JUJUY: Chilcayoc (Díaz 1999; Díaz \& Barquez 2007); León (Vitullo et al. 1986), León, $1500 \mathrm{~m}$ (Thomas 1918); San León de Jujuy (Kajon et al. 1984 como Oxymycterus akodontius).

\section{Oligoryzomys cf. O. flavescens}

Especimenes examinados. CATAMARCA: aprox. $2 \mathrm{~km}$ al SE de Huaico Hondo, sobre Ruta Provincial No 42, al E del Portezuelo, 1992 m (JPJ 424, 802); aprox. $10 \mathrm{~km}$ al W de Los Varela, sobre Ruta Provincial No 4, Sierra de Humaya, 2006 m (JPJ 1306, 1307, 1310); Las Chacritas, aprox. 28 km al NNW de Singuil, sobre Ruta Provincial No 1, 1888 m (JPJ 525, 541); unión entre las rutas provinciales $\mathrm{N}^{\circ} 9$ y 18, $3.4 \mathrm{~km}$ al S, sobre Ruta Provincial No 18, 1529 m (JPJ 9, 11, 13, 1112). JUJUY: La Antena, Sierra del Centinela, al S de El Fuerte, 2350 m (JPJ 965); La Herradura, 12 km al SW de El Fuerte, sobre Ruta Provincial No 6, 1428 m (JPJ 620); Termas de Reyes, aprox. 15 km al N, sobre Ruta Provincial No 4 (JPJ 294). SALTA: Pampa Verde, aprox. $8 \mathrm{~km}$ al OSO de Los Toldos y al S del Cerro Bravo, 2400 m (JPJ 344, 347, 353, 354, 358, 365). TUCUMÁN: aprox. $7 \mathrm{~km}$ al NO de la finca de la familia Usandivara, Altos de Medina, 1717 m (JPJ 818, 841, 851-853); aprox. $10 \mathrm{~km}$ al S de Hualinchay, 
sobre el camino a Lara, 2316 m (JPJ 987, 997, 998, 1005); Cumbre del Taficillo, al NE de Las Agüitas, Parque Biológico Sierra de San Javier (JPJ 120); Hualinchay, sobre el camino a Cafayate, 1861 (JPJ 247); La Angostura, barranca de los roedores (PEO-e 14); Villa Nougués, aprox. $2 \mathrm{~km}$ al N, sobre Ruta Provincial $\mathrm{N}^{\mathrm{o}} 338$, a la altura de la antena repetidora del Canal 10 de televisión (JPJ 256); Zanjón de Tafí, $2 \mathrm{~km}$ al sudoeste de Tafí del Valle, $2000 \mathrm{~m}$ (PEO-e 181).

Registros adicionales. Mares et al. (1997) y Díaz (1999) mencionaron a O.flavescens para $6 \mathrm{~km} \mathrm{SW}$ Hwy 9 on Hwy 18, 1524 m, en la provincia de Catamarca y para Cerro Calilegua, El Duraznillo, 2600 m en Jujuy respectivamente (véase también Díaz \& Barquez 2007 para esta última localidad). Ortiz \& Pardiñas (2001) citaron a Oligoryzomys cf. O. flavescens para La Angostura, en Tucumán. Dada la identificación realizada por estos autores y considerando que en los pastizales de neblina sólo hemos registrado dos formas para este género, es probablemente que estos ejemplares pertenezcan a la forma aquí tratada.

\section{Oligoryzomys sp.}

Especimenes examinados. CATAMARCA: aprox. $10 \mathrm{~km}$ al W de Los Varela, sobre Ruta Provincial $\mathrm{N}^{\mathrm{o}}$ 4, Sierra de Humaya, $2006 \mathrm{~m}$ (JPJ 1311); Las Chacritas, aprox. $28 \mathrm{~km}$ al NNW de Singuil, sobre Ruta Provincial No 1, 1888 m (JPJ 563, 564, 565); Mogote Las Trampas, aprox. 15 km al NW de Chumbicha, $2300 \mathrm{~m}$ (JPJ 1464); unión entre las rutas provinciales $\mathrm{N}^{\circ} 9$ y 18, $3.4 \mathrm{~km}$ al S, sobre Ruta Provincial No 18, 1529 m (JPJ 25, 46, 1118, 1122, 1130, 1136, 1138, 1139, 1140, 1154). JUJUY: Arroyo La Tablada (MMPMa 1237); Arroyo La Tablada, León (MMPMa 1253, 1266); Bárcena, aprox. $3 \mathrm{~km}$ al S, sobre Ruta Nacional No 9, 1808 m (JPJ 643-645, 653, 660-662, 665); La Herradura, 12 km al SW de El Fuerte, sobre Ruta Provincial No 6, 1428 m (JPJ 595, 597-599, 607, 613, 614, 616, 618, 619, 621, 622); León, Arroyo La Tablada (MMPMa 1252, 1261, 1265, 1268, 1269); Termas de Reyes, aprox. 15 $\mathrm{km}$ al N, sobre Ruta Provincial No 4 (JPJ 329); Termas de Reyes, mirador, sobre Ruta Provincial No 4 (JPJ 297, 298, 304, 319). SALTA: aprox. 15 km al W de Escoipe, sobre Ruta Provincial № 33, $2680 \mathrm{~m}$ (JPJ 1055); Campo Quijano aprox. $5 \mathrm{~km}$ al NO, km 30 de la ruta Nacional 51 (Quebrada del Toro), alt. app. 1600 m (JPJ 133); El Corralito, aprox. 23 km al SO de Campo Quijano, sobre ruta Nac. N 51 (JPJ 144, 149). TUCUMAN: aprox. $10 \mathrm{~km}$ al S de Hualinchay, sobre el camino a Lara, $2316 \mathrm{~m}$ (JPJ 760, 981, 982, 986, 1000, 1009, 1222); cumbre del Taficillo, al NE de Las Agüitas, Parque Biológico Sierra de San Javier (JPJ 112, 114, 116, 118); Horco Molle, Taficillo (CML 3999); Hualinchay, sobre el camino a Cafayate, 1861 (JPJ 209, 243, 249); La Angostura, barranca de los roedores (PEO-e 28); La Cruz, Cumbre del Taficillo, Parque Biológico Sierra de San Javier, 1907 m (JPJ 870, 894, 911, 920); Villa Nougués, aprox. $2 \mathrm{~km}$ al N, sobre Ruta Provincial N ${ }^{\circ} 338$, a la altura de la antena repetidora del Canal 10 de televisión (JPJ 282).

Registros adicionales. Ejemplares registrados por Díaz (1999) y Díaz \& Barquez (2007) para las localidades León; León, 1500 m y Mountains W of Yala, todas en la Provincia de Jujuy, probablemente pertenezcan a esta forma. Esta autora identificó los ejemplares como $O$. destructor, especie perteneciente al grupo nigripes de Carleton \& Musser (1989) y ampliamente distribuida en los Andes del sur de Colombia, Ecuador, Perú y Bolivia. Ortiz \& Pardiñas (2001) citaron a Oligoryzomys cf. $O$. longicaudatus para La Angostura, en la provincia de Tucumán, la cual probablemente corresponda también a esta forma. Seguramente esta es la situación de los ejemplares citados como O. longicaudatus por Mares et al. (1997) para Catamarca (véase el tratamiento de esta especie).

\section{Calomys lepidus}

Especimenes examinados. SALTA: aprox. $15 \mathrm{~km}$ al W de Escoipe, sobre Ruta Provincial $\mathrm{N}^{\mathrm{o}} 33$, 2680 m (JPJ 84).

Registros adicionales. SALTA: Valle Encantado, Los Cardones National Park, $3000 \mathrm{~m}$ (Ortiz et al. 2000). 


\section{Calomys musculinus}

Especimenes examinados. CATAMARCA: Agua del Gauchi, aprox. $1 \mathrm{~km}$ al E del Mogote Los Cocos, 2024 m (JPJ 1253, 1255, 1269-1271); Buena Vista, 3 km al sur, Las Estancias, $1700 \mathrm{~m}$ (PEO-e 191); El Espinillo, Campo del Pucará, Las Estancias, extremo sur de la Sierra del Aconquija, $1950 \mathrm{~m}$ (PEO-e 124); km 33 de la Ruta Provincial No 47, al S de Capillitas, 2500 m (JPJ 679, 692, 694, 696, 709); Loma Atravesada, aprox. $3 \mathrm{~km}$ al NO del puesto de Leandro Vega, NO de Chumbicha (JPJ 1170); Mogote Las Trampas, aprox. $15 \mathrm{~km}$ al NW de Chumbicha, $2300 \mathrm{~m}$ (JPJ 1420, 1433-1435, 1445-1448, 1450, 1455-1458, 1470, 1473). JUJUY: Bárcena, aprox. $3 \mathrm{~km}$ al S, sobre Ruta Nacional № 9, $1808 \mathrm{~m}$ (JPJ 131, 667). SALTA: Cuesta del Obispo, aprox. $5 \mathrm{~km}$ al NE de Piedra del Molino, sobre Ruta Provincial No 33, 3174 m (JPJ 1216); Valle Encantado, Parque Nacional Los Cardones, 3000 m (PEOe 114). TUCUMÁN: Carapunco, km 81 de la Ruta Provincial N 307, 2960 m (JPJ 1070, 1075, 1100, 1101, 1103); El Rincón, vertiente oeste de la Loma Pelada, Valle de Tafí, 2300 m (PEO-e 163); La Angostura, barranca de los roedores (PEO-e 30); Zanjón de Tafí, 2 km al sudoeste de Tafí del Valle, $2000 \mathrm{~m}$ (PEO-e 183).

Registros adicionales. CATAMARCA: El Rodeo, $0.75 \mathrm{~km} \mathrm{~S}$ village limits along Hwy 4, $1372 \mathrm{~m}$; Otro Cerro, $3000 \mathrm{~m}$ (Olds 1988 como C. murillus). JUJUY: 1 mi. W León, $5800 \mathrm{ft}$ (Olds 1988); $9 \mathrm{~km}$ NW Bárcena; Chilcayoc; León, 1.6 km al O, 1770 m (Díaz 1999 y Díaz \& Barquez 2007). TUCUMÁN: El Infiernillo (Dalby \& Mares 1974); Nr. Tucumán, Mala Mala (Olds 1988); Ñorco Vipos, 2500 m (Olds 1988 como C. murillus).

\section{Phyllotis osilae}

Especimenes examinados. CATAMARCA: Agua del Gauchi, aprox. $1 \mathrm{~km}$ al E del Mogote Los Cocos, 2024 m (JPJ 1228-1232, 1241-1244, 1247, 1250-1252, 1257, 1258, 1260, 1272-1276, 1281, 1288, 1289, 1293-1297); aprox. 2 km al SE de Huaico Hondo, sobre Ruta Provincial № 42, al E del Portezuelo, 1992 m (JPJ 412, 781, 790); aprox. $10 \mathrm{~km}$ al W de Los Varela, sobre Ruta Provincial No 4, Sierra de Humaya, 2006 m (JPJ 1312); El Espinillo, Campo del Pucará, Las Estancias (PEO-e 126); El Rodeo, $1.5 \mathrm{~km}$ NE of Hwy 4, el: $4500 \mathrm{ft}$ (CML 3448); Estancia Narvaez, 5.5 Km N Las Chacritas en Ruta Provincial No 1, 1782 m (liberado); km 33 de la Ruta Provincial No 47, al S de Capillitas, $2500 \mathrm{~m}$ (JPJ 674, 676, 677, 680, 681, 685, 686, 688, 693, 695, 702-707, 713, 715); Las Chacritas, aprox. $28 \mathrm{~km}$ al NNW de Singuil, sobre Ruta Provincial No 1, 1888 m (JPJ 567, 568); Loma Atravesada, aprox. 3 km al NO del puesto de Leandro Vega, NO de Chumbicha, 1369 m (JPJ 1157, 1159, 1162, 1167-1169); Mogote Las Trampas, aprox. 15 km al NW de Chumbicha, 2300 m (JPJ 1422, 1425-1428, 1430, 1439, 1440, 1449, 1451, 1459, 1460, 1461, 1469); Río Vallecito, 2900 m (MACN 50.441); unión entre las rutas provinciales No 9 y 18, 3.4 km al S, sobre Ruta Provincial No 18, 1529 m (JPJ 19, 24, 31, 41, 1127, 1129, 1132, 1137, 1149, 1156). JUJUY: Bárcena, 9 km NW, 2655 m (liberado); Bárcena, aprox. $3 \mathrm{~km}$ al S, sobre Ruta Nacional No 9, 1808 m (JPJ 632, 636-639, 646, 655, 668); Cerro Hermoso (MACM 19521-19540); El Duraznillo, Cerro Calilegua, 2600 m (CML 1724, 1725); La Antena, Sierra del Centinela, al S de El Fuerte, 2350 m (JPJ 933, 936, 940, 955, 956, 958, 962, 969, 970); Termas de Reyes, aprox. 15 km al N, sobre Ruta Provincial No 4 (JPJ 291, 315); Termas de Reyes, mirador, sobre Ruta Provincial No 4 (JPJ 122, 296, 324, 333, 334). SALTA: 1 km ENE de Rodeo Pampa, km 59 de Ruta Provincial No 7, 3080 m (JPJ 1313, 1314, 1316, 1319, 1323-1329, 1332, 1335-1339); Abra de Ciénaga Negra, aprox. $3 \mathrm{~km}$ al SE, $3090 \mathrm{~m}$ (JPJ 722, 723, 727, 738); aprox. $15 \mathrm{~km}$ al W de Escoipe, sobre Ruta Provincial No 33, $2680 \mathrm{~m}$ (JPJ 51, 57, 60, 65, 68, 71, 74, 86, 1034, 1043, 1048, 1056, 1057, 1059); Campo Quijano aprox. $5 \mathrm{Km}$ al NO, Km 30 de la ruta Nacional 51 (Quebrada del Toro), alt. aprox. 1600 m (JPJ 91, 92, 97, 98, 101-104, 135-137, 140-142); Cuesta del Obispo, aprox. 5 km al NE de Piedra del Molino, sobre Ruta Provincial No 33, 3174 m (JPJ 1210, 1214, 1215); Valle Encantado, Parque Nacional Los Cardones, $3000 \mathrm{~m}$ (PEO-e 115). TUCUMÁN: aprox. $7 \mathrm{~km}$ al NO de la finca de la familia Usandivara, Altos de Medina, 1717 m (JPJ 810, 831, 837, 839); aprox. $10 \mathrm{~km}$ al S de Hualinchay, sobre 
el camino a Lara, 2300 m (JPJ 435, 444, 451, 453, 456, 460, 461, 467, 469, 474, 476; 483, 487, 488, 771); aprox. 16 km de Hualinchay, sobre el camino a Lara, 2750 m (JPJ 746, 748, 749, 751, 765, 767, 769, 776, 777); Carapunco, km 81 de la Ruta Provincial N 307, 2960 m (JPJ 1063, 1071, 1078, 1083, 1099, 1102, 1104); Cerro Muñoz, arriba del Puesto de Ibáñez, subiendo por Santa Cruz, 3300 m (PEO 41, 43); Cerro Muñoz, Puesto de Ibáñez, subiendo por Santa Cruz, 2650 m (PEO 34, 35); Cerro San Javier, 2000 m (MACN 26.145); El Rincón, 1 km al N, 2450 m (PEO 2, 3); El Rincón, vertiente oeste de la Loma Pelada, Valle de Tafí, 2300 m (PEO-e 164); Hualinchay, 1.9 km NE, en Ruta Provincial N ${ }^{\circ}$ 311, 1732 m (liberado); Hualinchay, 2.2 Km NE, en Ruta Provincial № 311, 1732 m (liberado); Hualinchay, sobre el camino a Cafayate, 1861 (JPJ 173, 175, 176, 178, 183, 187, 189, 218, 220, 223, 227, 228); La Angostura, barranca de los roedores (PEO-e 32); SW de Hualinchay, 2822 (liberado); Zanjón de Tafí, 2 km al sudoeste de Tafí del Valle, 2000 m (PEO-e 184).

Registros adicionales. CATAMARCA: 6 km SW Hwy 9 on Hwy 18, 1524 m (Mares et al. 1997); $45 \mathrm{~km}$ west of Chumbicha, about $3000 \mathrm{~m}$ (Thomas 1919 como P. tucumanus); Aconquija, $3000 \mathrm{~m}$; Otro Cerro, 3000 m (Hershkovitz 1962 como P. o. tucumanus); Otro Cerro, 3018 m (Mares et al. 1997); Otro Cerro, $9900 \mathrm{ft}$ (Pearson 1958 como P. o. tucumanus). JUJUY: 1 mi. W León, $5800 \mathrm{ft}$ (Pearson 1958 como P. o. osilae); 9 km NW Bárcena; Chilcayoc; León, 1500 m (Díaz 1999, Díaz \& Barquez 2007 como P. o. osilae); León (Thomas 1918 como P. darwini tucumanus); Yala mountain west of, $10000 \mathrm{ft}$ (Hershkovitz 1962 como P. o. osilae). TUCUMÁN: above Tafí del Valle, $9500 \mathrm{ft}$; Cerro San Javier, 2000 m; Ciénaga; Cumbre de Mala Mala, Sierra de Aconquija, 3300 m (Hershkovitz 1962 como P. o. tucumanus); El Infiernillo (Dalby \& Mares 1974); La Ciénaga (=Ciénaga?), 8200 ft (Pearson 1958 como P. o. tucumanus); Las Paras, 3018 m (Mares et al. 1997); Las Paras, $9900 \mathrm{ft}$; Norco, $8200 \mathrm{ft}$ (Pearson 1958 como P. o. tucumanus); Ñorco, Vipos, 1500 - 2000 m; Tafí del Valle; Tafí del Valle, above (Hershkovitz 1962 como P. o. tucumanus); Tafí del Valle, $7000 \mathrm{ft}$ (Pearson 1958 como P. o. tucumanus); Tafí del Valle, $9500 \mathrm{ft}$ (Hershkovitz 1962 como P. o. tucumanus).

\section{Andinomys edax}

Especimenes examinados. CATAMARCA: Andalgalá, confluencia de los ríos Minas y Candado, 2600 m (CML 4814); El Espinillo, Campo del Pucará, Las Estancias, extremo sur de la Sierra del Aconquija, 1950 m (PEO-e 123); km 33 de la Ruta Provincial No 47, al S de Capillitas, 2500 m (JPJ 718); Otro Cerro, 3000 m (MACN 20.261). JUJUY: Cerro Hermoso (MACN 19.544, 19.554). SALTA: Aprox. $5 \mathrm{~km}$ (por ruta) al S de Los Toldos, sobre el camino a Vallecito, $1705 \mathrm{~m}$ (PEO-e 271); aprox. 15 km al W de Escoipe, sobre Ruta Provincial No 33, 2680 m (JPJ 1045, 1061, 1062); Valle Encantado, Parque Nacional Los Cardones, $3000 \mathrm{~m}$ (PEO-e 112). TUCUMAN: Aconquija, $3000 \mathrm{~m}$ (MACN 29.250-29.253, 30.72, 33.178); aprox. $10 \mathrm{~km}$ al S de Hualinchay, sobre el camino a Lara, $2316 \mathrm{~m}$ (JPJ 752, 1221, 1226, 1227); camino a Amaicha, km 83 (CML 670); Carapunco, km 81 de la Ruta Provincial N 307, 2960 m (JPJ 1064); Cerro Muñoz, arriba del Puesto de Ibáñez, subiendo por Santa Cruz, 3300 m (PEO 37); Cerro San Javier, 2000 m (MACN 26.147, 26.148); El Infiernillo (MACN 17.566); Hualinchay, sobre el camino a Cafayate, $1861 \mathrm{~m}$ (JPJ 254); Infiernillo, 3000 m (CML 688, 689); La Angostura, barranca de los roedores (PEO-e 29); sierra de Tafí Viejo, Tucumán, 2000 m (MACN 33.85); Zanjón de Tafí, 2 km al sudoeste de Tafí del Valle, $2000 \mathrm{~m}$ (PEO-e 182).

Registros adicionales. CATAMARCA: $45 \mathrm{~km}$ west of Chumbicha, about $3000 \mathrm{~m}$ (Thomas 1919). JUJUY: Cerro Hermoso (cercanías), $2800 \mathrm{~m}$; Duraznillar, $2500 \mathrm{~m}$ (Heinonen \& Bosso 1994); Mountains W of Yala (Hershkovitz 1962 como Andinomys edax edax); W of Yala (Steppan 1995). TUCUMAN: La Angostura (Ortiz \& Pardiñas 2001); Norco, Vipos, 2500 m (Hershkovitz 1962 como A. e. lineicaudatus); Taficillo (Capllonch et al. 1997).

\section{Neotomys ebriosus}

Especimenes examinados. SALTA: aprox. $15 \mathrm{~km}$ al W de Escoipe, sobre Ruta Provincial № 33, 2680 m, 1 (JPJ 87, 1052). 

2000).

Registros adicionales. SALTA: Valle Encantado, Los Cardones National Park, $3000 \mathrm{~m}$ (Ortiz et al.

\title{
Especies de presencia marginal en pastizales de neblina
}

\author{
Abrothrix andinus \\ Especimenes examinados. Ninguno. \\ Registros adicionales. CATAMARCA: Minas Capillitas, 3200 m (Mares et al. 1997 como Akodon \\ andinus). TUCUMAN: El Infiernillo (Dalby \& Mares 1974 como Akodon andinus).
}

\section{Abrothrix illuteus}

Especimenes examinados. CATAMARCA: Las Chacritas, aprox. $28 \mathrm{~km}$ al NNW de Singuil, sobre Ruta Provincial No 1, $1888 \mathrm{~m}$ (JPJ 520, 549, 551, 569, 572). TUCUMAN: aprox. $10 \mathrm{~km}$ al S de Hualinchay, sobre el camino a Lara, 2300 m, (JPJ 481, 501, 763, 774, 922, 992, 993, 1220); La Angostura, barranca de los roedores (PEO-e 25); Las Agüitas, cumbre del Taficillo (CML 4020, 4021, 4036); Tafí Viejo, cerros occidentales (CML 297, 301); Zanjón de Tafí, 2 km al sudoeste de Tafí del Valle, $2000 \mathrm{~m}$ (PEO-e 178).

Registros adicionales. Villa Nougués (Bianchi et al. 1971 como "Akodon" illuteus).

\section{Akodon aliquantulus}

Especimenes examinados. TUCUMAN: Las Agüitas, cumbre del Taficillo (CML 6121 paratipo, 6122 holotipo).

Registros adicionales. Ninguno.

\section{Akodon budini}

Especimenes examinados. JUJUY: Cerro Hermoso (MACN 19470, 19471, 19473, 19475-19482); El Duraznillo, Cerro Calilegua, 2600 m (CML1738-1741, 1743-1751); León, (MMPMa 2192, 18.1.1.46 y 8 ejemplares s/n); León, Arroyo La Tablada, (MMPMa 1545, 1251, 1258, 1260). SALTA: aprox. 5 km (por ruta) al S de Los Toldos, sobre el camino a Vallecito, 1705 m (JPJ 1578-1580, 1582, 1591, 1595, 1602, 1606, 1609, 1613, 1616, 1632, 1659, 1674, 1681, 1682, 1687, 1689, 1691, 1722, 1728, ); Pampa Verde, OSO de Los Toldos y al S del Cerro Bravo, 2400 m, (JPJ 336, 351, 368).

Registros adicionales. JUJUY: Duraznillar, 2500 m (Heinonen \& Bosso 1994); León, $1500 \mathrm{~m}$ (Thomas 1918 como Hypsimys budini).

\section{Akodon fumeus}

Especimenes examinados. SALTA: Aprox. $5 \mathrm{~km}$ (por ruta) al S de Los Toldos, sobre el camino a Vallecito, 1705 m (JPJ 1594, 1599, 1605, 1614, 1626-1628, 1634, 1638, 1650, 1656, 1657, 1660, 1663, 1664, 1667, 1670, 1680, 1683, 1693, 1696, 1697, 1712, 1716, 1721, 1730). 2007).

Registros adicionales. JUJUY: Cerro Calilegua, El Duraznillo, 2600 m (Díaz 1999, Díaz \& Barquez

\section{Necromys amoenus}

Especimenes examinados. SALTA: 1 km ENE de Rodeo Pampa, km 59 de Ruta Provincial $\mathrm{N}^{\circ} 7$, $3080 \mathrm{~m}$ (JPJ 1317, 1318, 1333).

Registros adicionales. Ninguno.

\section{Necromys sp.}

Especimenes examinados. TUCUMAN: Las Agüitas, cumbre del Taficillo (CML 5989)

Registros adicionales. Ninguno.

\section{Oxymycterus sp.}

Especimenes examinados. TUCUMÁN: aprox. $10 \mathrm{~km}$ al S de Hualinchay, sobre el camino a Lara, 2316 m (JPJ 753, 762, 772, 921, 923, 1407); Zanja del Chivo, La Angostura, 1850 m (PEO-e 3).

Registros adicionales. Ninguno. 
Jayat, Ortiz \& Miotti. Sigmodontinos de pastizales de neblina

\section{Calomys fecundus}

Especimenes examinados. TUCUMÁN: La Angostura, barranca de los roedores (PEO-e 31).

Registros adicionales. TUCUMÁN: La Angostura (Ortiz \& Pardiñas 2001 como C. venustus); El Infiernillo Dept., NW of Tafí del Valle (Olds 1988 como C. venustus).

\section{Graomys edithae}

Especimenes examinados. Ninguno.

Registros adicionales. CATAMARCA: $45 \mathrm{~km}$ west of Chumbicha, about $3000 \mathrm{~m}$ (Thomas 1919); Otro Cerro, $3000 \mathrm{~m}$ (Mares et al. 1997); Otro Cerro, about $18 \mathrm{~km} \mathrm{NNW}$ of Chumbicha, $3000 \mathrm{~m}$ (Hershkovitz 1962).

Especimenes examinados. Ninguno.

\section{Graomys griseoflavus}

Registros adicionales. CATAMARCA: $45 \mathrm{~km}$ west of Chumbicha, about $3000 \mathrm{~m}$ (Thomas 1919 como G. cachinus y G. medius); Minas Capillitas, 3200 m; Otro Cerro (Mares et al. 1997); Otro Cerro, 3000 m (Hershkovitz 1962 como Phyllotis griseoflavus).

\section{Phyllotis anitae}

Especimenes examinados. TUCUMAN: $10 \mathrm{~km}$ by road south of Hualinchay on the trail to Lara (CML 6379-6381; CNP 736, 737, 809).

Registros adicionales. Ninguno.

\section{Phyllotis caprinus}

Especimenes examinados. JUJUY: Bárcena, aprox. $3 \mathrm{~km}$ al S, sobre Ruta Nacional No 9, $1808 \mathrm{~m}$ (JPJ 132, 624, 626, 640, 671); Chilcayoc, Puente Bailey, aprox. $4.6 \mathrm{~km}$ al NO de la intersección de la Ruta Nacional No 9 y el camino hacia el Puente Bailey, 2239 m (JPJ 130).

Registros adicionales. JUJUY: 9 km NW Bárcena; Chilcayoc (Díaz 1999, Díaz \& Barquez 2007).

\section{Phyllotis xanthopygus}

Especimenes examinados. CATAMARCA: Agua del Gauchi, aprox. $1 \mathrm{~km}$ al E del Mogote Los Cocos, 2024 m (JPJ 1286); Mogote Las Trampas, aprox. $15 \mathrm{~km}$ al NW de Chumbicha, $2300 \mathrm{~m}$ (JPJ 1421, 1423, 1431, 1432, 1441, 1442, 1444, 1453, 1454, 1468, 1471, 1472, 1474, 1475). SALTA: $1 \mathrm{~km}$ ENE de Rodeo Pampa, km 59 de Ruta Provincial No 7, 3080 m (JPJ 1331); Cuesta del Obispo, aprox. $5 \mathrm{~km}$ al NE de Piedra del Molino, sobre Ruta Provincial No 33, 3174 m (JPJ 1213); Valle Encantado, Parque Nacional Los Cardones, 3000 m (PEO-e 116).

Registros adicionales. CATAMARCA: $45 \mathrm{~km}$ west of Chumbicha, about $3000 \mathrm{~m}$ (Thomas 1919 como Phyllotis ricardulus); El Rodeo, 1.5 km NE Hwy 4, 1372 m; Minas Capillitas, $3200 \mathrm{~m}$ (Mares et al. 1997 como P. darwini); Otro Cerro, 3000 m (Hershkovitz 1962 como P. darwini rupestris); Otro Cerro, 3018 m (Mares et al. 1997 como P. darwini); Otro Cerro, $9900 \mathrm{ft}$ (Pearson 1958 como P. darwini ricardulus). JUJUY: Cerro Hermoso (Díaz 1999, Díaz \& Barquez 2007); Cerro Hermoso (cercanías), 2800 m; Duraznillar, 2500 m (Heinonen \& Bosso 1994 como P. darwini). SALTA: Valle Encantado, 3500 m; Valle Encantado, C. del Obispo (Díaz et al. 2000).

\section{Tapecomys wolffsohni}

Especimenes examinados. SALTA: Santa Victoria O, 2100 (MACN 17719); Santa Victoria O, 2200 (MACN 17723).

Registros adicionales. Ninguno.

\section{Reithrodon auritus}

Especimenes examinados. CATAMARCA: El Espinillo, Campo del Pucará, Las Estancias, extremo sur de la Sierra del Aconquija, 1950 m (PEO-e 127).

Registros adicionales. CATAMARCA: Otro Cerro (Mares et al. 1997); Otro Cerro, 3000 m (Thomas 1920 como R. caurinus); Otro Cerro, southermost Sierra de Ambato (Pardiñas \& Galliari 2001). TUCUMAN: El Infiernillo (Barquez et al. 1991); Paso El Infiernillo; Sierra de Aconquija (Pardiñas \& Galliari 2001). 


\section{Especies de presencia dudosa}

\section{Oligoryzomys chacoensis}

Especimenes examinados. Ninguno.

Registros adicionales. JUJUY: Chilcayoc (Díaz 1999, Díaz \& Barquez 2007).

\section{Calomys laucha}

Especimenes examinados. Ninguno.

Registros adicionales. TUCUMÁN: Ñorco (= Ñorco Simbolán), Tucumán at 1500-2000 m (Hershkovitz 1962).

\section{Eligmodontia moreni}

Especimenes examinados. Ninguno.

Registros adicionales. CATAMARCA: Mina Capillitas, 3200 m (Mares et al. 1997).

Recibido: 28 de septiembre de 2007

Aceptado: 20 de mayo de 2008 
